\title{
الاتجاهات الحديثة في توظيف تقتيات إدارة المعرفة في مؤسسات التعليم العالي السعودية
}

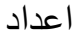 \\ د.نورة بنت ناصر التهزاني

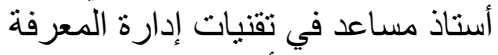

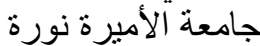

الملخص:

تعتبر تقنيات إدارة المعرفة الركيزة الأساسية لإدارة المعرفة فهي أداة تخزين ونقل ومشاركة المعرفة

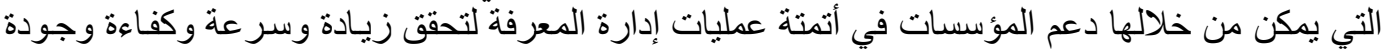

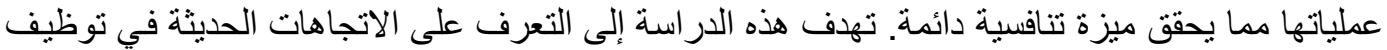

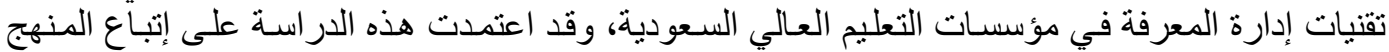

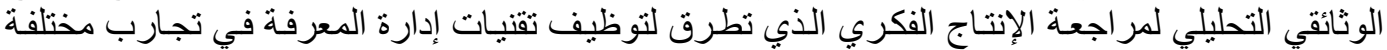

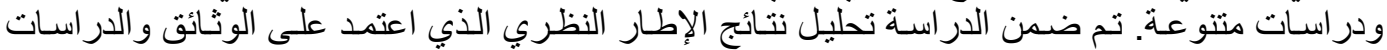

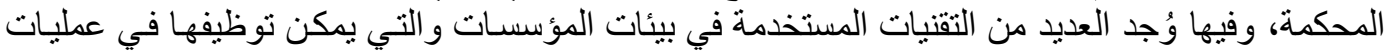

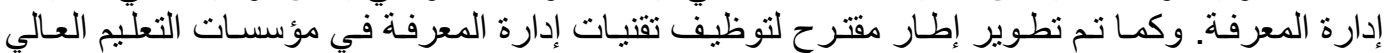

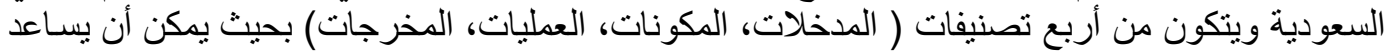

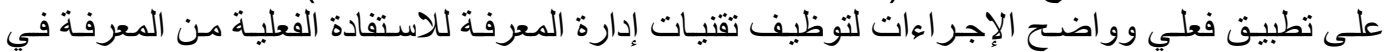

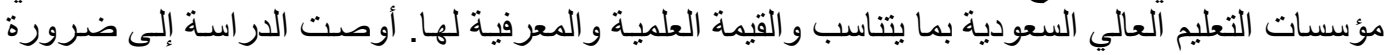

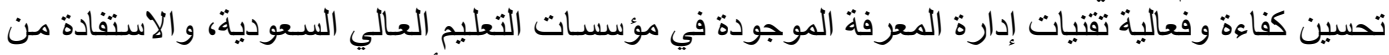

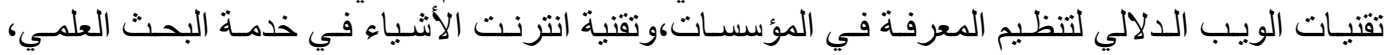

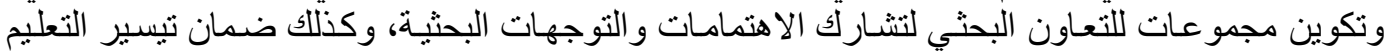

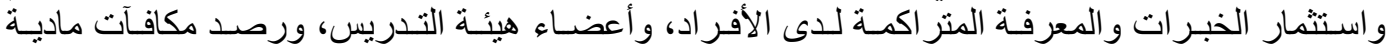

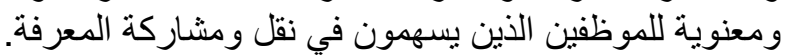

الكلمات المفتاحيةة: تقنيات إدارة المعرفة، إدارة المعرفة، عمليات إدارة المعرفة، مؤسسات التعليم العالي.

المقدمة :

تتعدد الوسائل التقنية التي تُستخدم لتحويل المدخلات التنظيمية إلى مخرجات تسـاهم في إدارة المعرفة

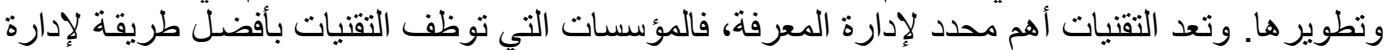

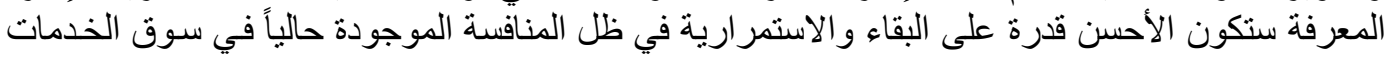
المعرفية .

يعمل استخدام تقنيات إدارة المعرفة على جمع وتصنيف وتخزين وتوصيل أو مشاركة المعرفة بين

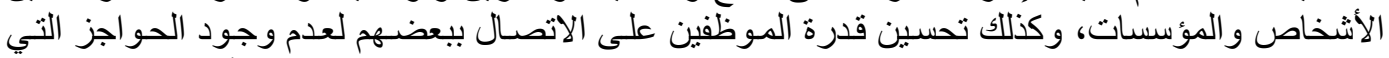

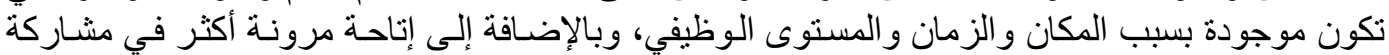

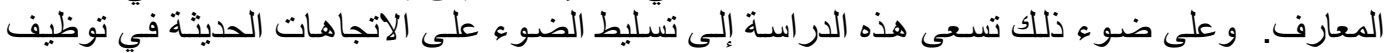

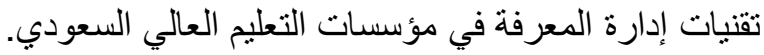

مشكلة الدارسة:

تو اجه بعض مؤسسات التعليم العالي السعودية قصوراً في وجود تقنيات معرفيـة لدعم توجهها نحو

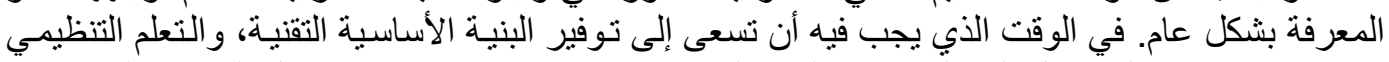

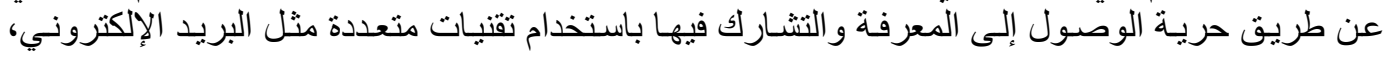




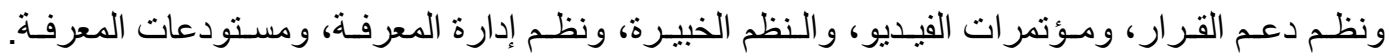

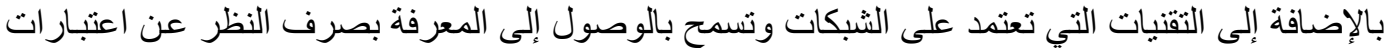

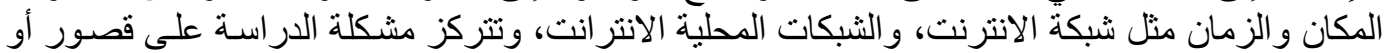

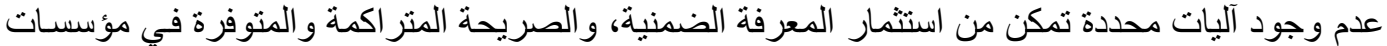

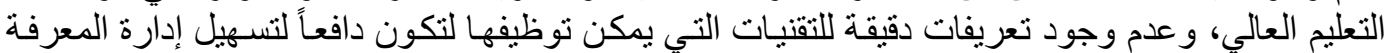
واستخدامها بشكل سهل وعل ومضمون.

\section{مصطلح الاراسة:}

تقتيات إدارة المعرفة Knowledge Management techniques:هي الوسـائل المتقدمـة

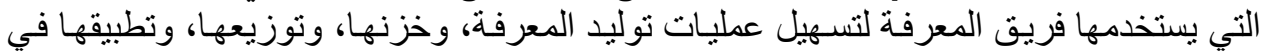

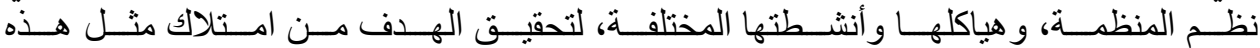

التقنيات(Daft:2006,150).

إدارة المعرفة Knowledge Management: هي تللك الإدارة التي تعمل على التعرف على ملى مارف

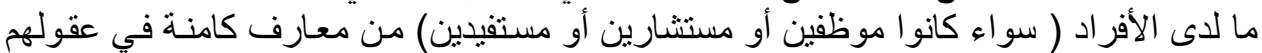

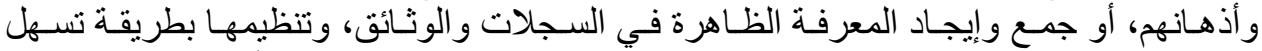

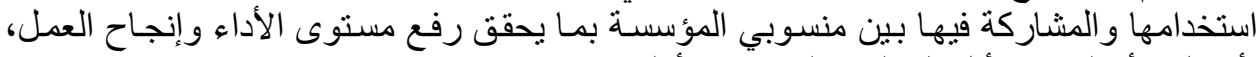

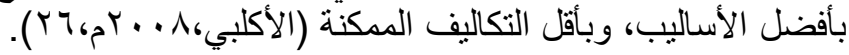

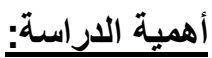

الكشف عن الدور الذي تلعبـه تقنيات إدارة المعرفـة في مؤسسـات التعليم العـالي السـودية، ممـا

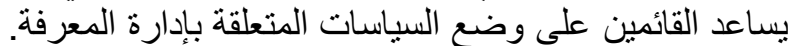

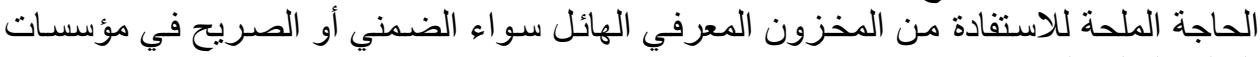
التعليم العالي السعودية. مساهمة الدر"اسة في تحديد وتعريف التقنيات الأساسية لإدارة المعرفة و التي بالإمكان أن تستخدم لتحسين، وتطوير اختيار ها في مؤسسات التعليم العالي السعودية.

أهداف الاراسة:

تتمثل أهداف الدراسة في ما يلي: التعرف على الاتجاهـات الحديثة في توظيف تقنيات إدارة المعرفة في مؤسسـات التعليم العـالي السعودية. • رصد أفضل تقنيات إدارة المعرفة المستخدمة على مستوى العالم.

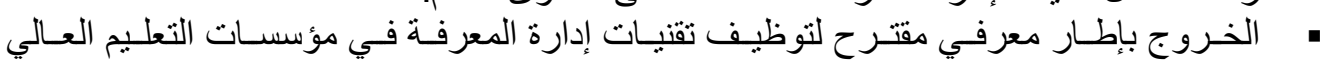
السعودية.

\section{منهج الدراسة:}

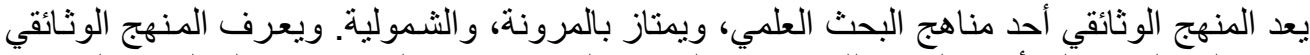

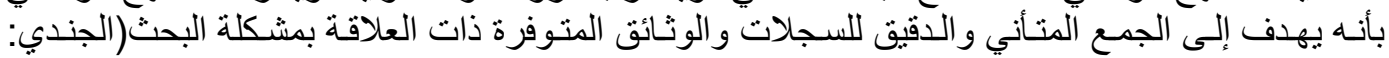

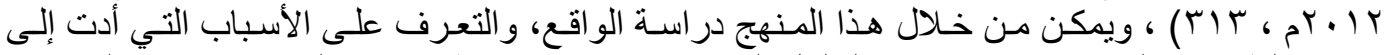

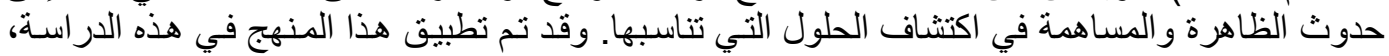




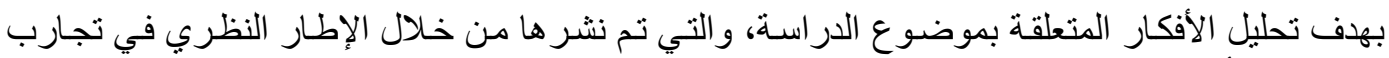

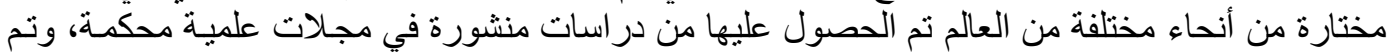

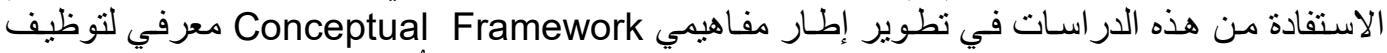

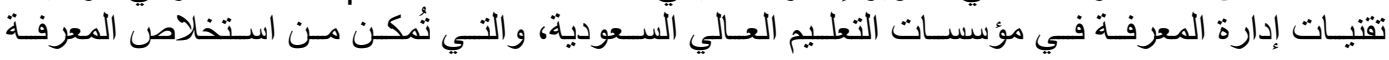

ومشاركتها.

حدود الار اسةة:

• الحدود الموضـوعية : تنحصـر في الإنتـاج الفكري المتعلـق بتوظيف تقنيـات إدارة المعرفـة و المو اضيع ذات العلاقة.

الحدود الزمنية: تقتصر على الإنتاج الفكري والمتعلق بتوظيف تقنيات إدارة المعرفة من قبل إنبل

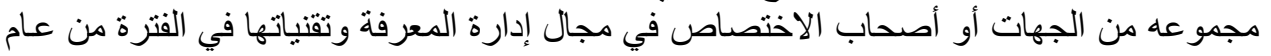

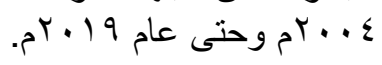

الار اسات السابقة:

سيتم عرض الدر اسـات السـابقة اعتمـاداً على التبـع الزمني لها مـن الأحدث إلى الأقدم على النحو

در اسة الباحث Almalky (9 19 • بم) بعنوان" إدارة المعرفة في الموارد البشرية في شركات النفط

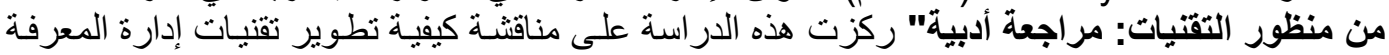

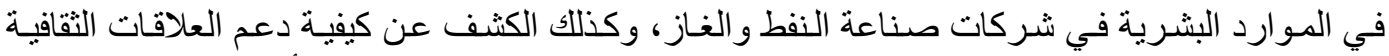

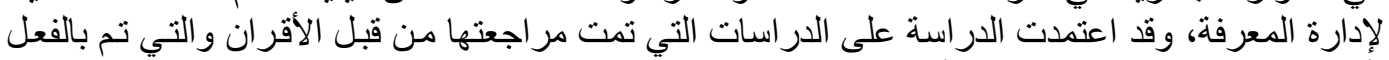

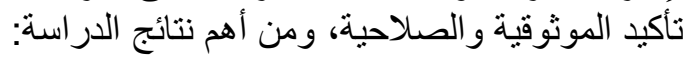

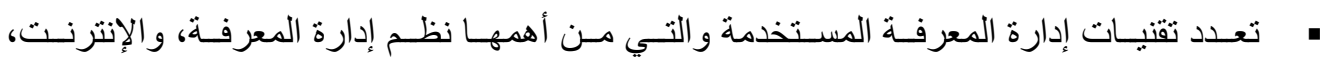

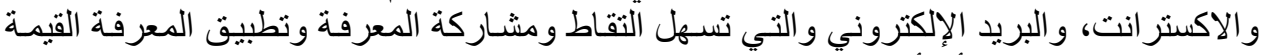

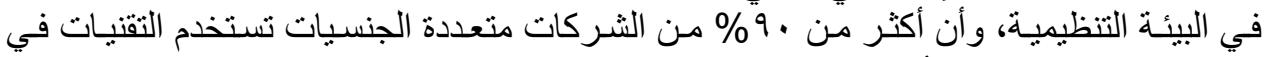

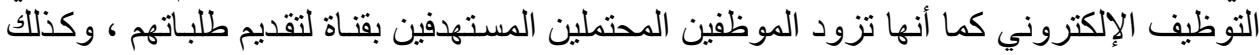

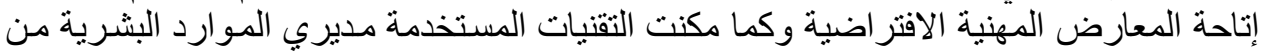
توظيف موظفين ذوي مهار ات خاصة مثل مطوري البرة البر امج. تعزيز تقنيـات إدارة المعرفـة التعـاون في التدريب والإرشـاد و التـي تـودي إلى تطوير الفردي وتحسين الأداء.

كثنت دعم تقنيات إدارة المعرفة أنشطة إدارة المعرفة الموارد البشرية بطرق عديدة من تعزيز إنيز

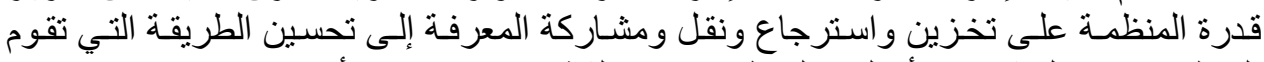
المنظمات بتشكيل ثقافتها و أساليب التوظيف والثئ وبناء الثقة و الانفتاح بين الأعضاء.

وكان أهم التوصيات :

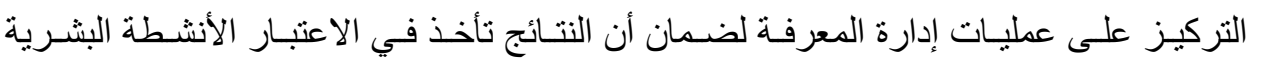
المختلفة والتي تعتبر حيوية لخلق المعرفة (143-2019,136: (Almalky). 


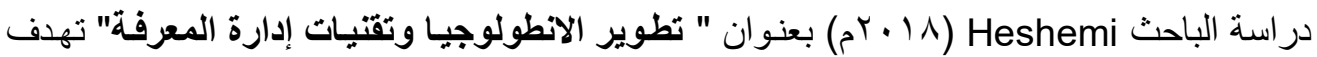

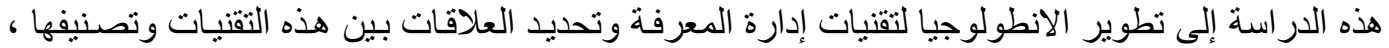

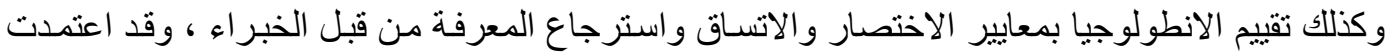

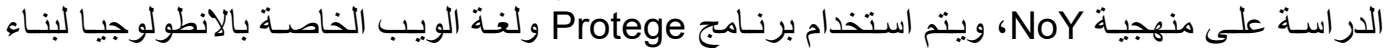
وتطوير انطولوجيا تقنيات إدارة المعرفة وكان من أهم أنتائج الدراسة:

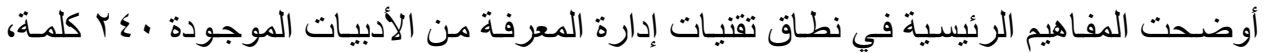

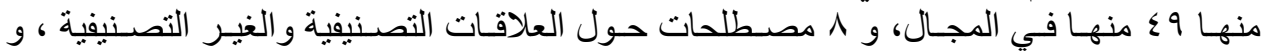

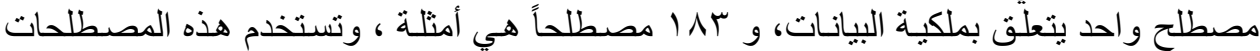

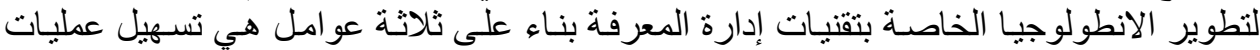

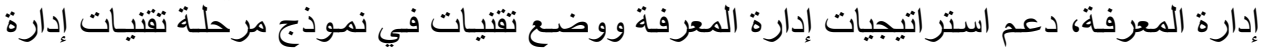

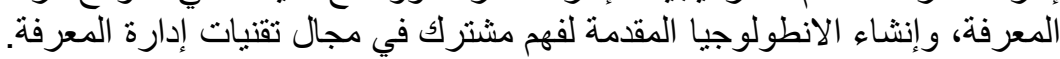
توصلت إلى مزايا الانطولوجيا في خلق فهم مشترك في مجال معين. كثفت عن التحديات الرئيسية وهي عدم الإلمام خبر اء الانطولوجيا بتمثيل لغات المعرفة الرسمية وكذلك أدوات تحرير الانطولوجيا مما يعيق مشاركة الخبير في نطوير المعرفة في هذا الإنو المجال. أسهمت انطولوجيا تقنيات إدارة المعرفة الرسمية في تو افر منصسة لمشـاركة معرفة الخبر اء من الن جميع أنحاء العالم. ( Heshemi:2018,28-99).

در اسـة الباحث

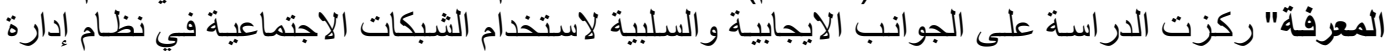

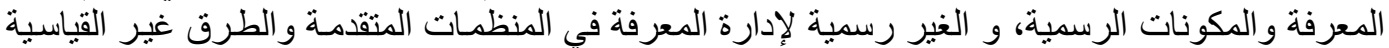

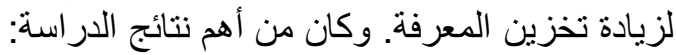

• أشارت أن الشبكات الاجتماعية أداة ايجابية قوية لنشر المعرفة وزيادتها في المنظمة.

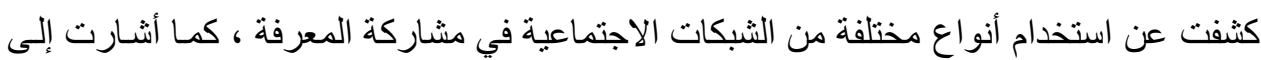

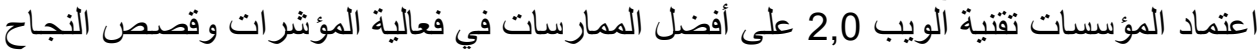
و الاروس المستفادة.

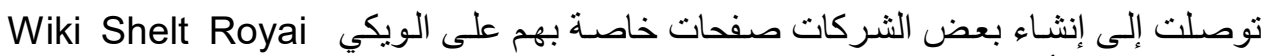

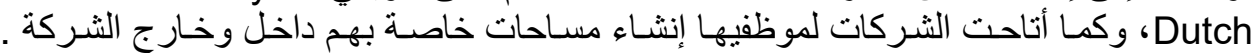

(Oseledchik: 2018,911-914)

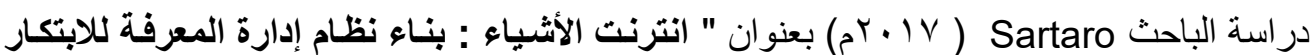

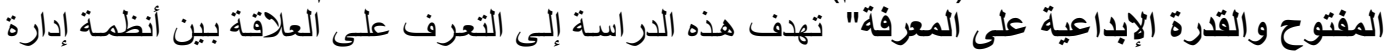

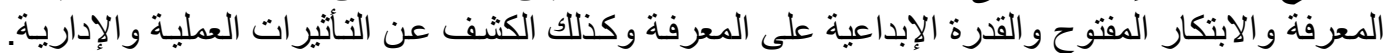

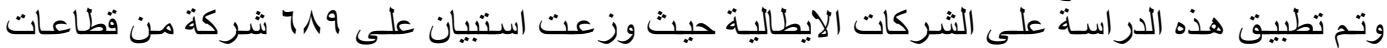
مختلفة و أحجام مختلفة وركزت على المديرين التنفيذين ومديري CTO للعمل كخبيرين رئيسين وذلكانك لأنسه

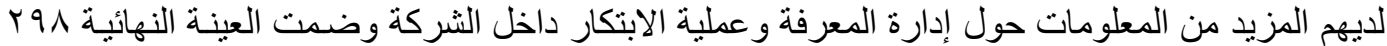

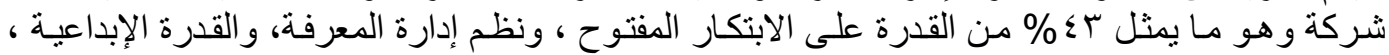
و إدارة المعرفة وكان من أهم نتائج الدراسة: 
تقدم انترنـت الأشـياء فرصـا جديدة لتحسين ممارسـات إدارة المعرفـة وزيـادة تدفق المعرفـة مـن

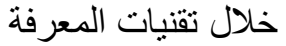

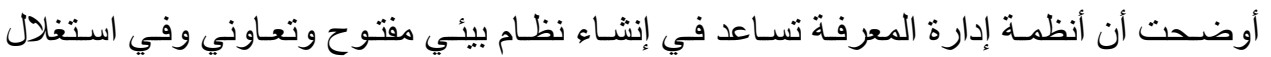

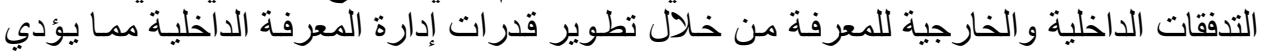
بدوره إلى زيادة القدرة على الابتكار أثنارت أن نظام إدارة المعرفة يساعد في تخزين، ودمج المعرفة الصريحة، و الضمنية التي تعزز من استغلال المعرفة.(Sartaro:2017,1-30).

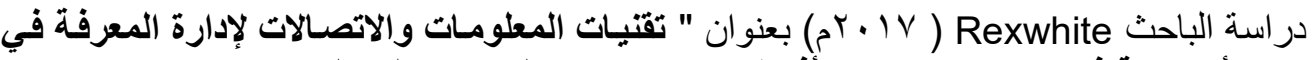

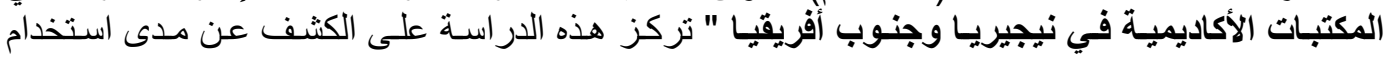

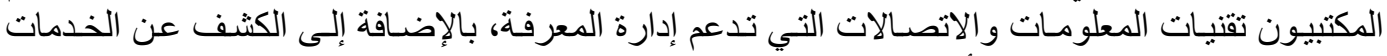

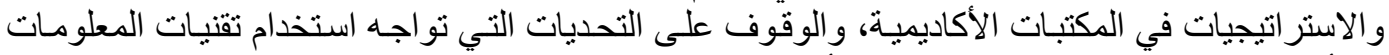

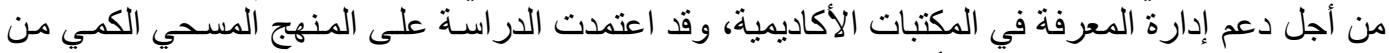

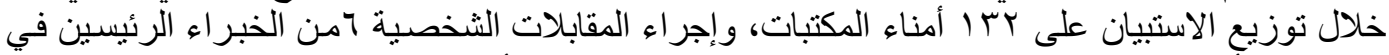

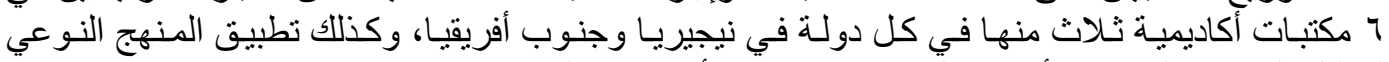

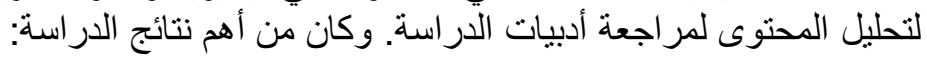

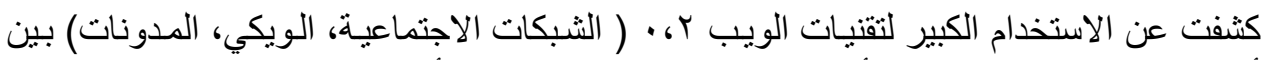

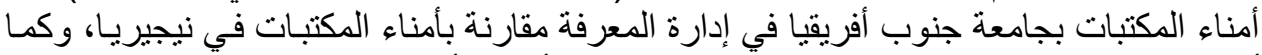

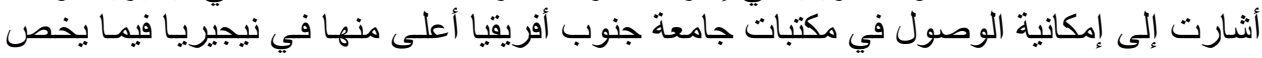
البريد الإلكتروني، والفهرس التعام، ومستخلصات النصوص النصوص.

أوضحت أهم الأسباب لاستخدام تقنيات المعلومـات و هي دعم البحث العلمي، وتطوير المنـاهج

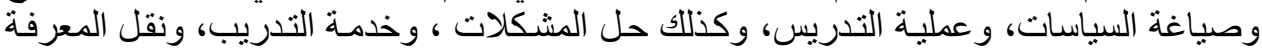
الموجودة وتوليد المعرفة الجديدة.

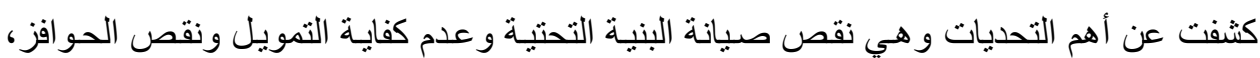
و عدم كفاية الموظفين الفنيين وهي أكثر وضوحا في المكتبات الأكاديمية في نيجيريا

\section{وكان من أهم التوصيات:}

تكثيف تطوير الموظفين لتمكين الكيفية التي يمكن للمكتبين التعامل مـع التغير ات و التقنيات الجديدة لخدمات المعلومات الحديثة. (Rexwhile:2017,1-9)

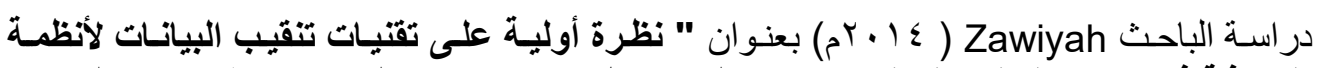

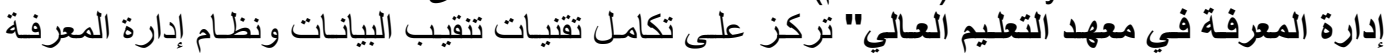

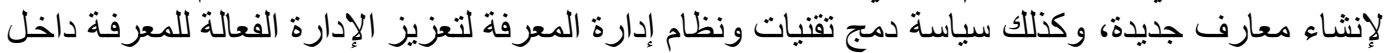

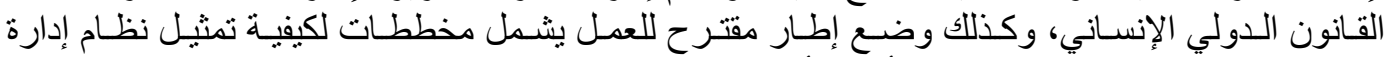

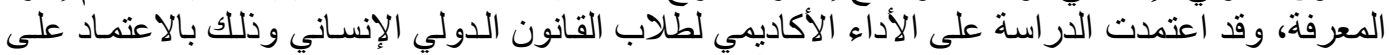

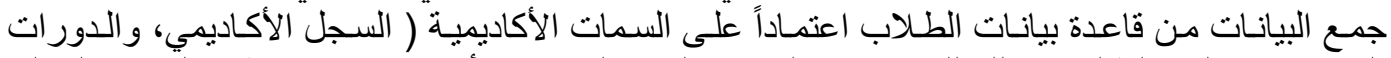

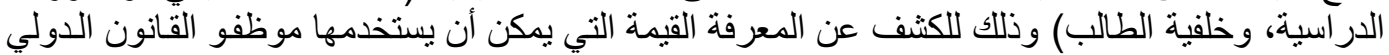

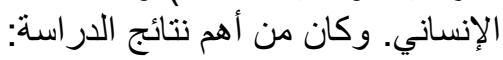


كثنت عن قدرة تنقيب البيانـات إنشاء معرفة قيمـة لاستخدامها في المسـاعدة على اتخـاذ القرار

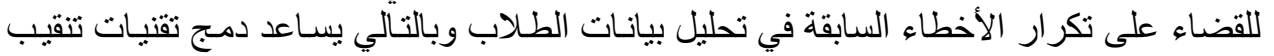

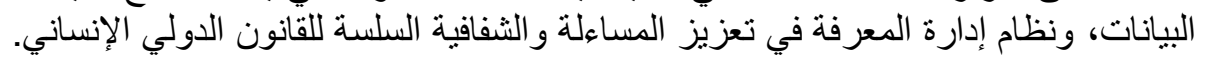
أوضحت الإطار المقترح لوحدات تكوين المعرفة والتي شملت ثناث وحدات و هي وحدة خلق

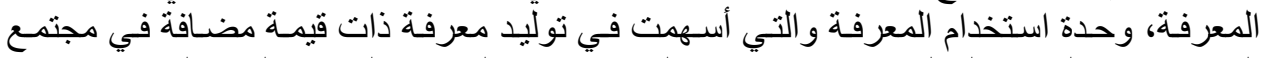

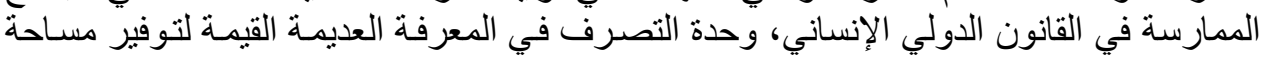

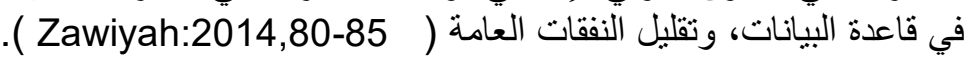

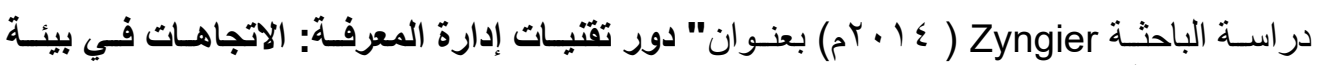

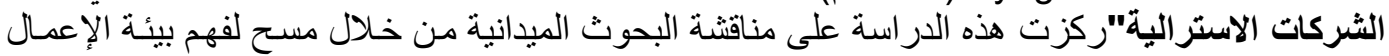

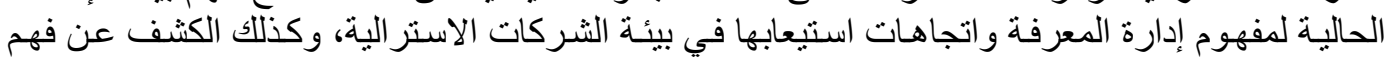

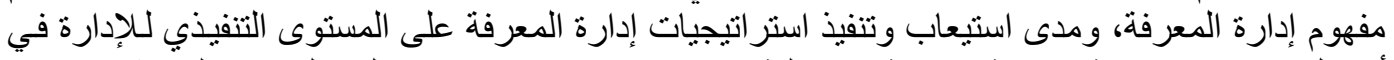

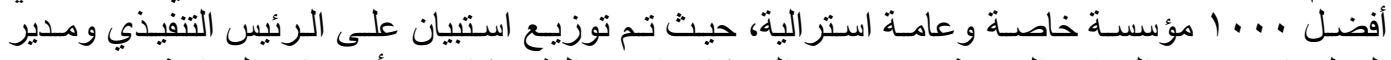

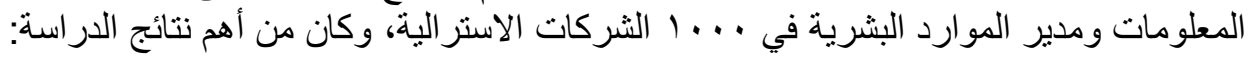

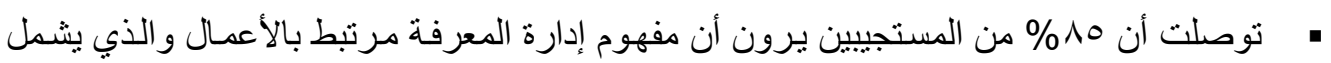

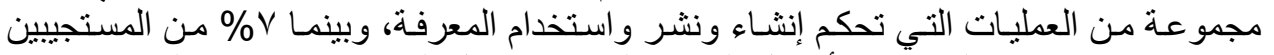

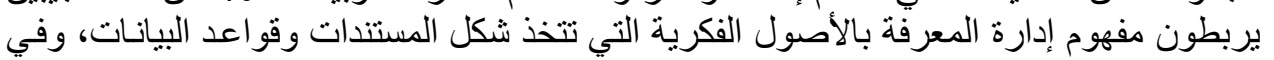

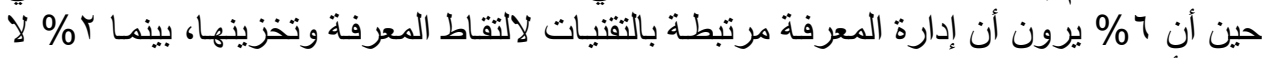
يرون أن مفهوم إدارة المعرفة ان عملية مرئية. أوضحت أن · 9\% من الشركات التي شملتها الدر اسة تستخدم شبكة الانتر انت على نطاق و اسـع

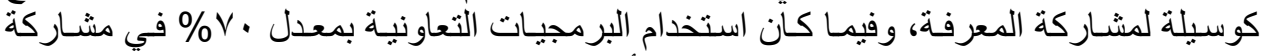

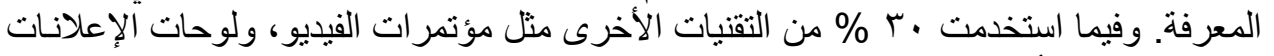

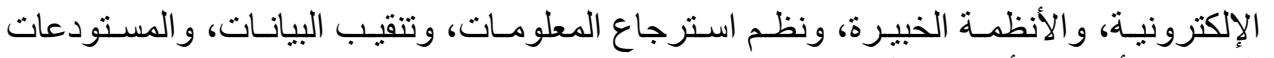

$$
\text { الرقمية، وأنظمة الأرشفة الإلكترونية. ( Zyngier:2014, 1-12). }
$$

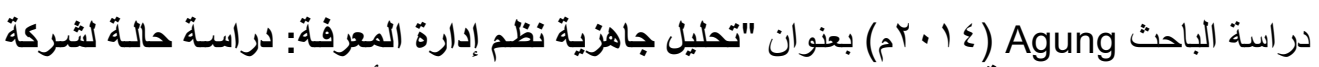

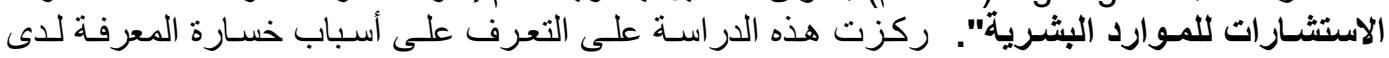

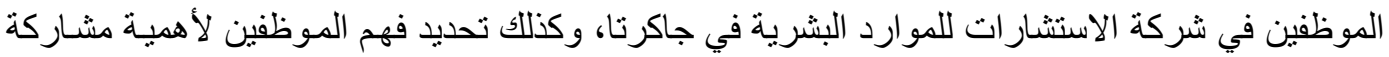

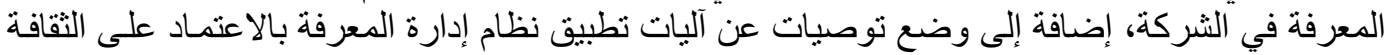

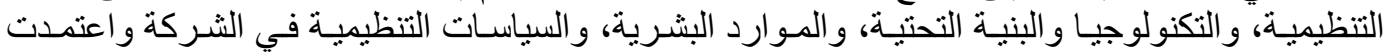

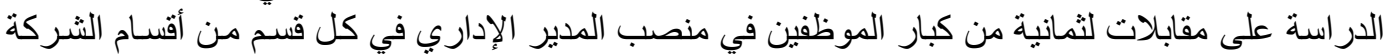

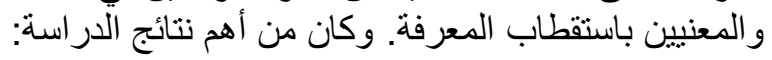

عدم وجود آلية لنظام إدارة المعرفة لتوثيق المعرفة وتوزيع المعرفة التي بمتلكها الموظفين بحيث في حالة استقالة الموظف أو تقاعده أو موته تفقد الثركة الثرة معرفة الموظة المونف.

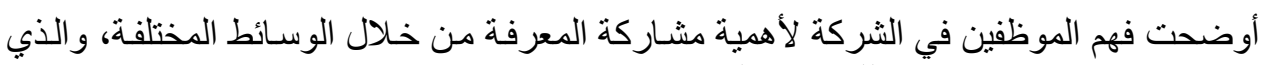
بدوره يسهم في وضع سيأسة للموظفين ليكونون نشيطين في مشاركة معارفهر. 


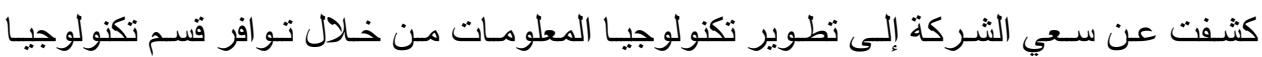

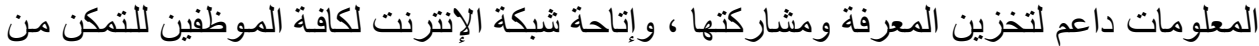
مشاركة المعرفة وتوليدهما في أي وقت ومثرأي وأي مكان.

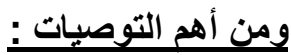

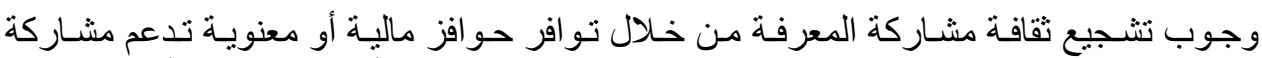
الموظفين بمعارفه، بالإضافة إلى تضمين مشاركة المعرفة كمؤشر أداء في تقييم الأداء الوظيفي

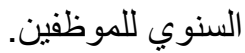

وجوب تبني آلية وسياسة واضحة لجميع الموظفين عن كيفية الوصول إلى المعرفة ومشـاركتها عبر نظام إدارة المعرفة KMS.

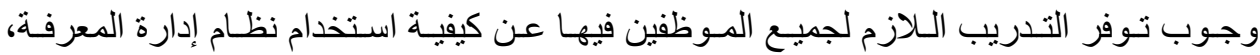

وخاصة في ظل وجود قسم تكنولوجيا المعلومات في الثركة. (Agung:2014, 205-210).

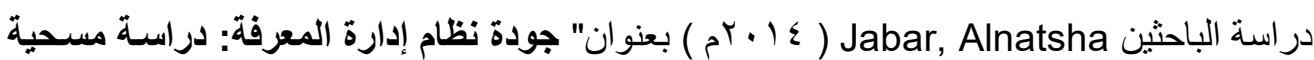

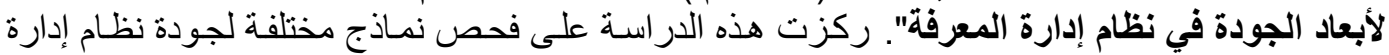

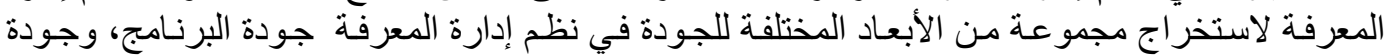

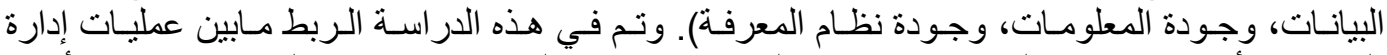

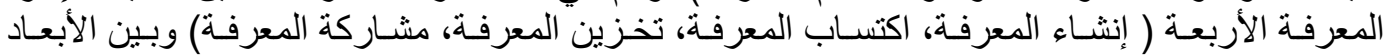

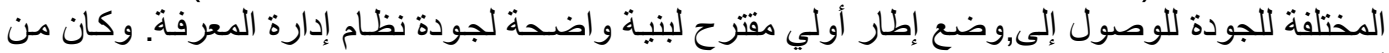

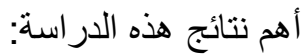

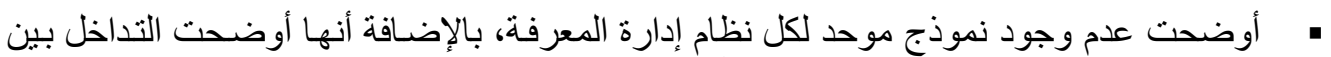

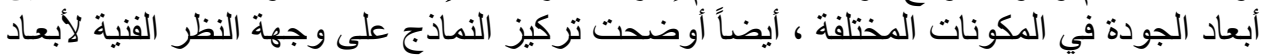

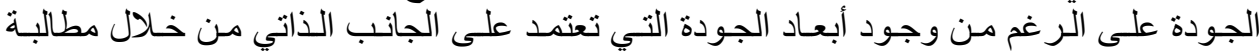

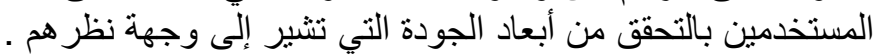

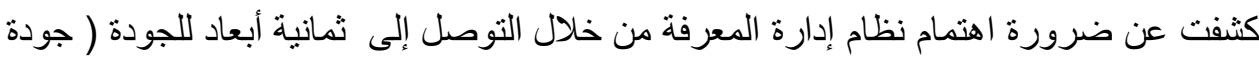

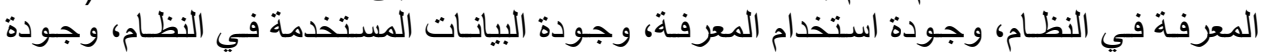

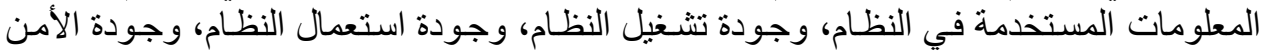
المعلوماتي للنظام، وجودة مرونة النظام).(Jabar:2014, 1-5).

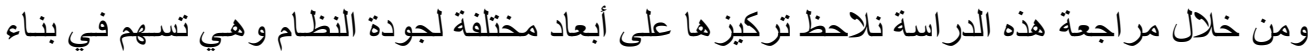

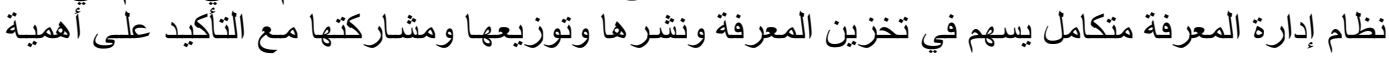
وجهة نظر المستخدمين لنظام.

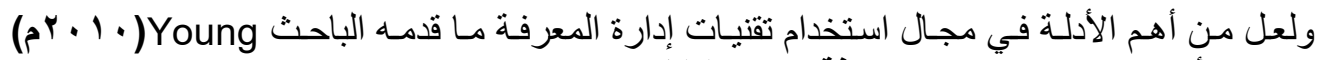

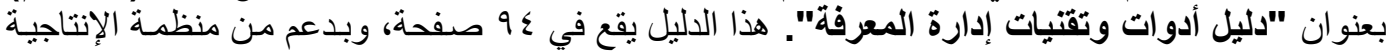

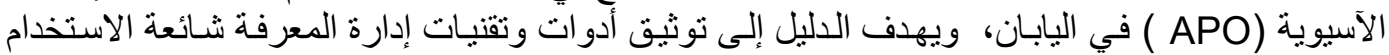

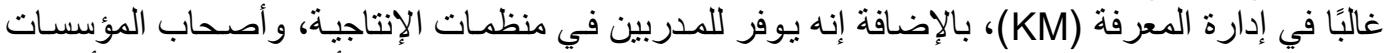

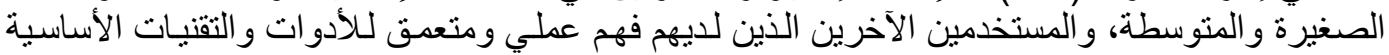

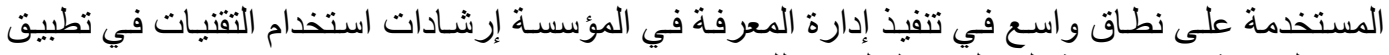
إدارة المعرفة، وبالإضافة إلى الروابط المفيدة للمواقع. 


$$
\text { وقد صنف الأساليب والأدوات إلى صنفين هما: }
$$

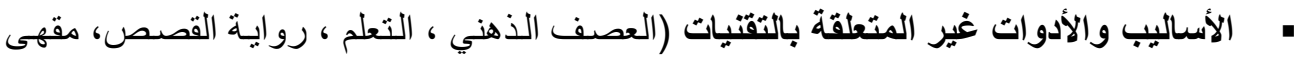

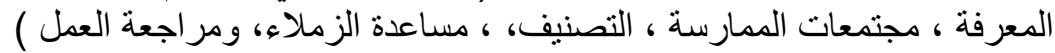

طــرق وأدوات تقتيـات المعرفـة ( نظـام إدارة الوثـائق ، قو اعـد المعرفـة (الـويكي ، إلــخ.)

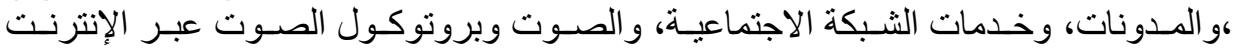
(VOIP)

وخلص الدليل إلى وضع إطار عمل لمنظمة الإنتاجية الآسيوية (APO) حيث اشتمل على فهم الرؤيسة

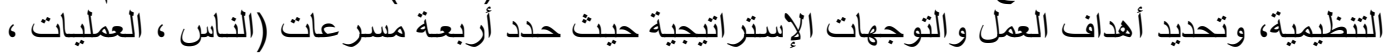

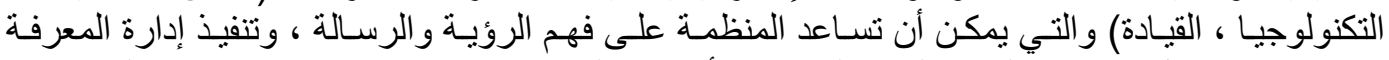

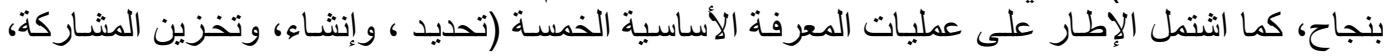

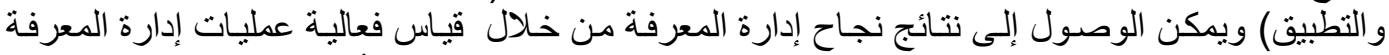

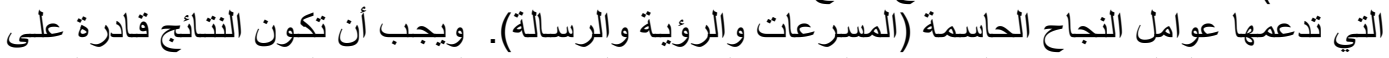

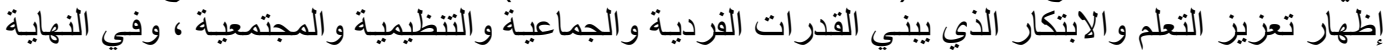
تؤدي إلى تحسينات في جودة المنتجات و الخدمات و الإنتاجية و الربحية والنمو (

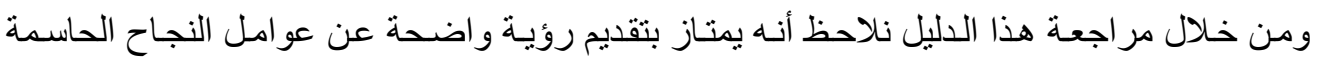

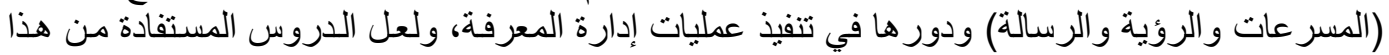

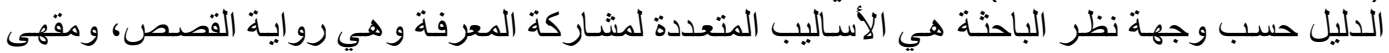

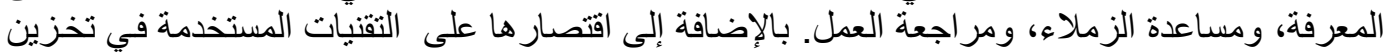

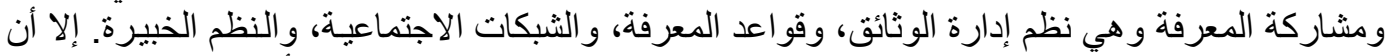

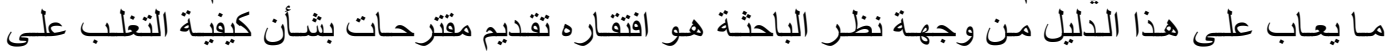

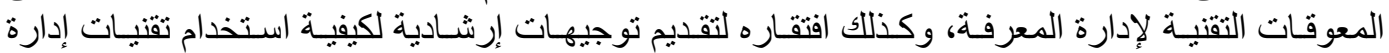

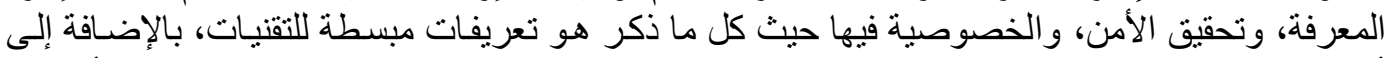

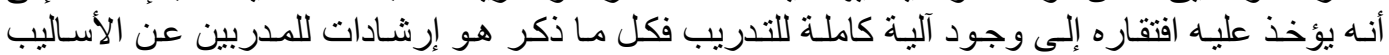
و التقنيات المستخدمة في تطبيق إدارة المعرفة.

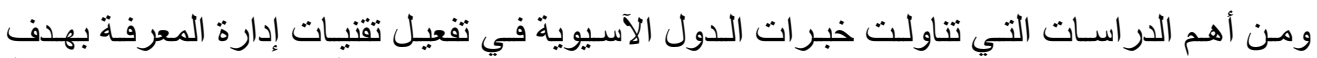

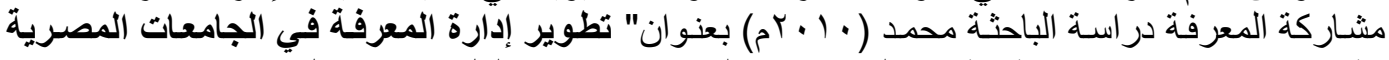

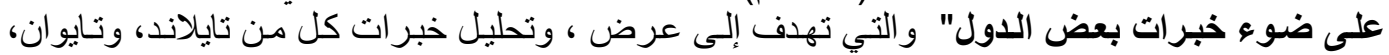

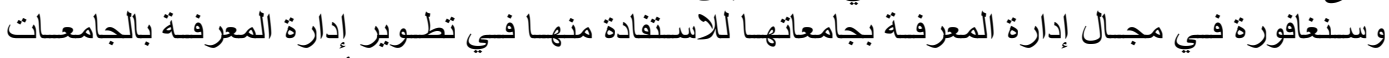

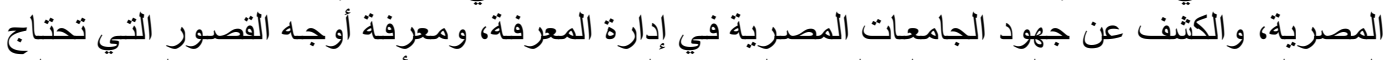

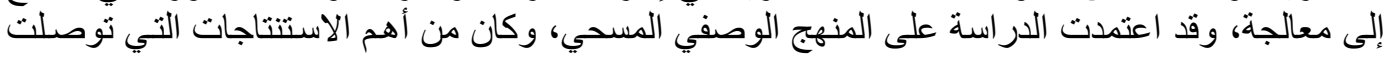

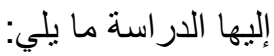

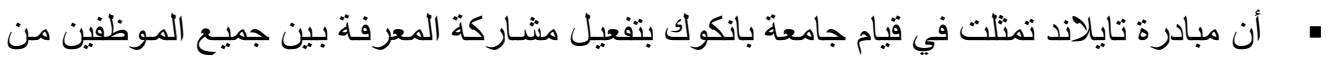

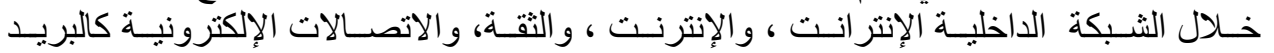

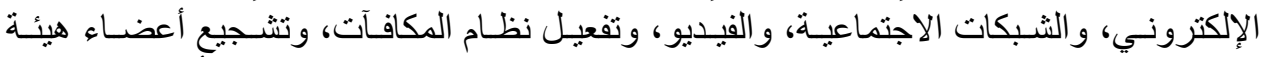

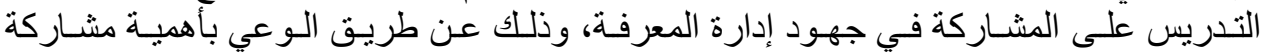
معارفهم مع الآخرين. 
• أن مبادرة سنغافورة تمثلت في قيام جامعة سنغافورة للإدارة من خلال إنشـاء مستودعات المعرفة

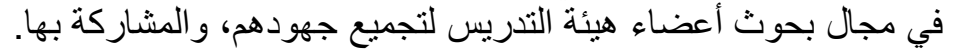

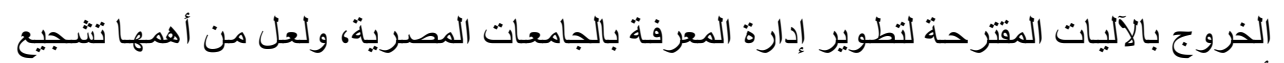

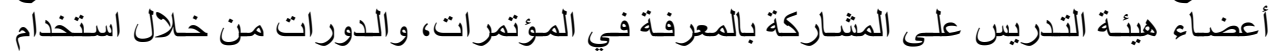

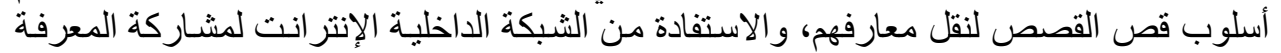

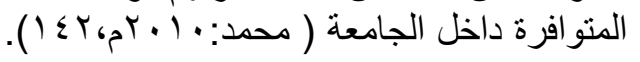

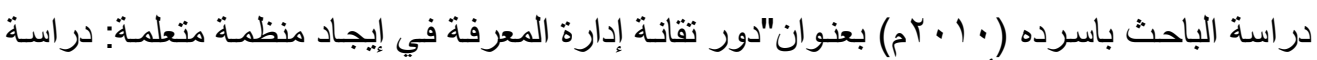

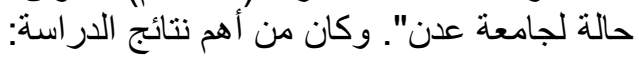

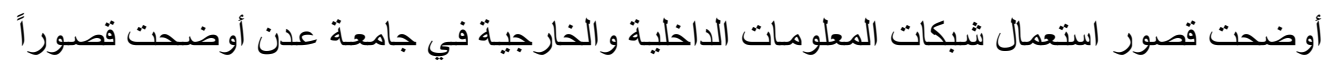

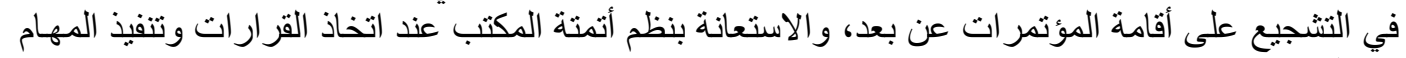

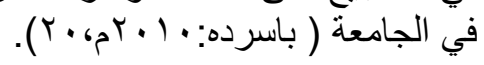

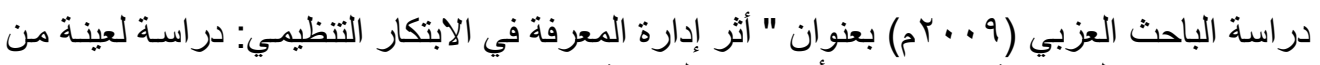

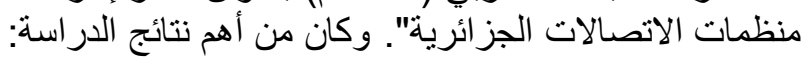

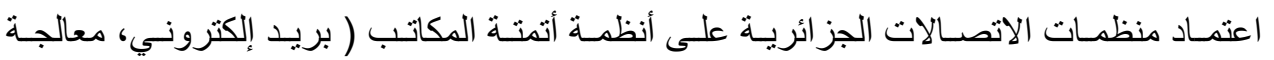

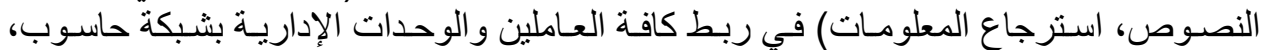

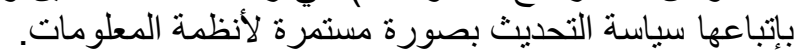

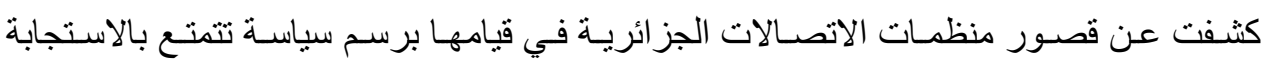

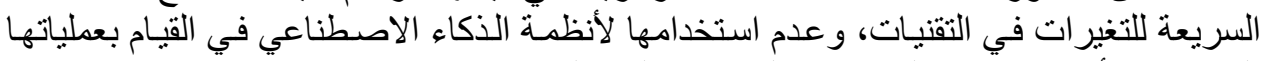

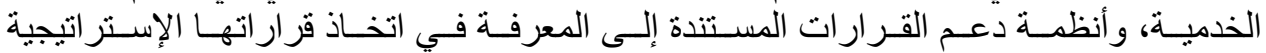

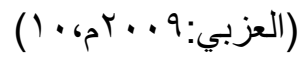

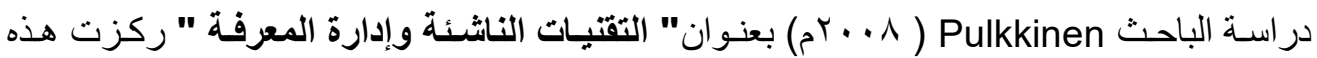

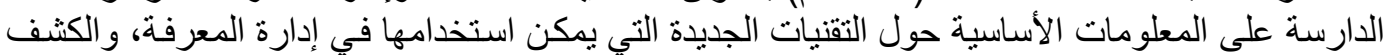

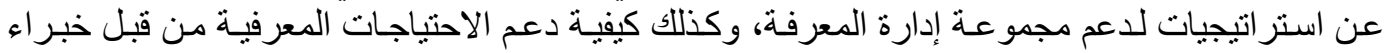

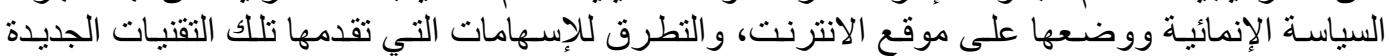

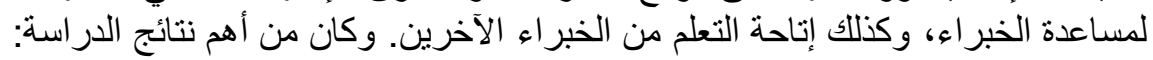

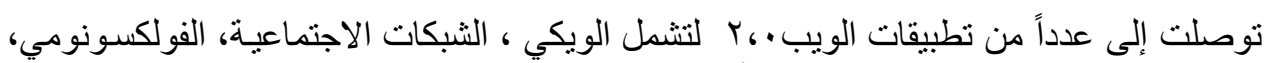

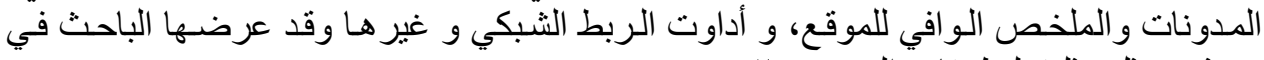

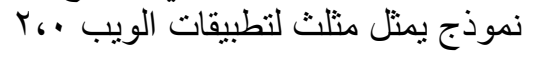
كثفت عن تطورات الويـب الدلالي ومـدى أسـهام تطبيقاتها في أداء إدارة المعرفـة مسن خـلال المساهمة في تكامل خلق المعرفة وآست البتخدامها. أشارت إلى استخدام الحوسبة المنتشرة والتي تعرف أيضـا بالحوسبة في كل مكان وهي تشمل

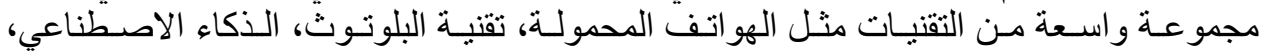

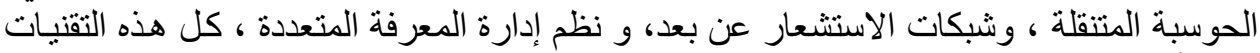

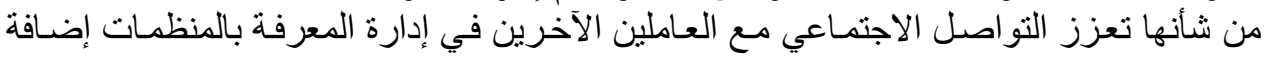


إلى تبادل المعرفة وتقاسمها واختز انها في قواعد البيانات المختصـة بالمنظمـات مما يمكن أتاحتها

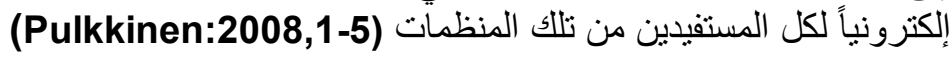

من خلال مر اجعة هذه الدر اسة نلاحظ تنوع التقنيات والتي تمثل دور كبير في عمليات إدارة المعرفة

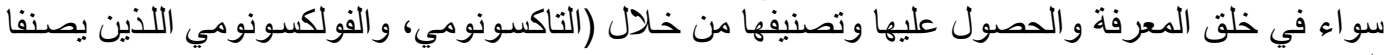
المعرفة في بيئة الانترنت أمعرو ومن ثم نشر ها وتوزيعها.

و ون الدراسات التحليليـة التي تعني بجانب التقنيات المستخدمة لإدارة المعرفة بالمؤسسـات التعليميـة

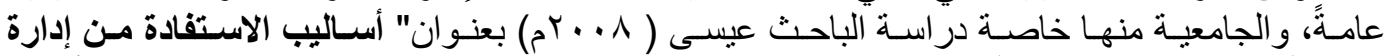

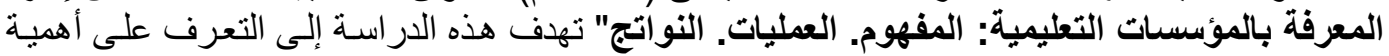

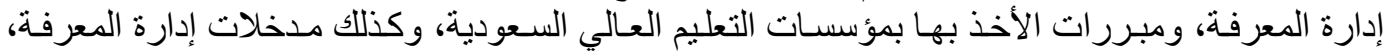

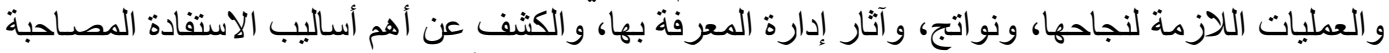

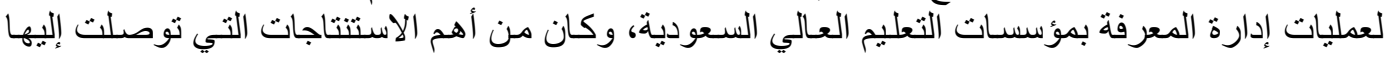

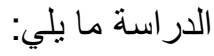

• اعتماد المؤسسات الجامعية على التقنيات الحديثة في تثخيص المعرفة، وتحديد أهدافها، كالنظم

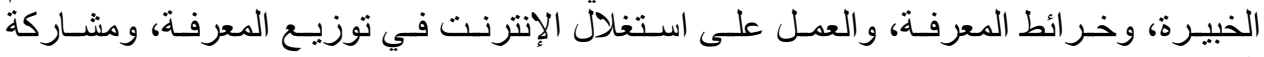

المعرفة.

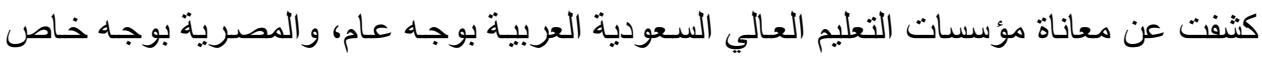

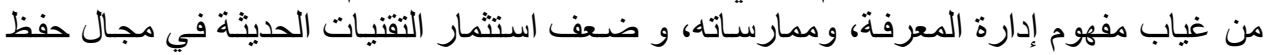

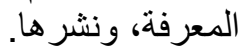

\section{وكان من أهم التوصيات:}

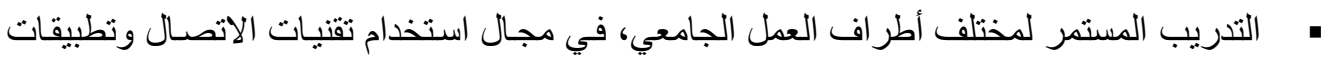

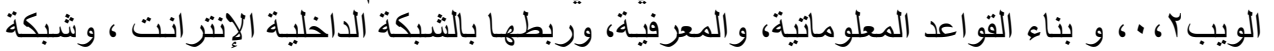

الإنترنت.

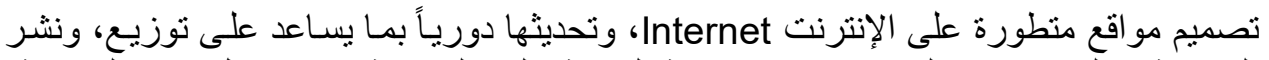

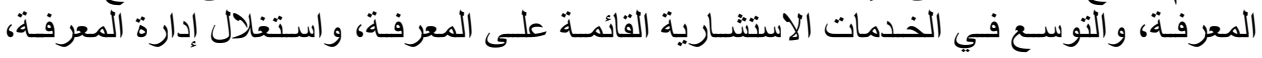

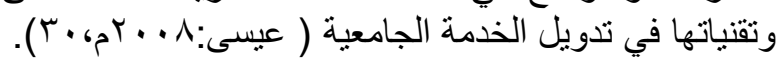

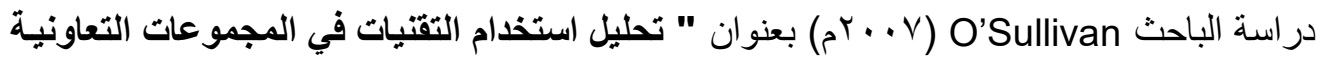

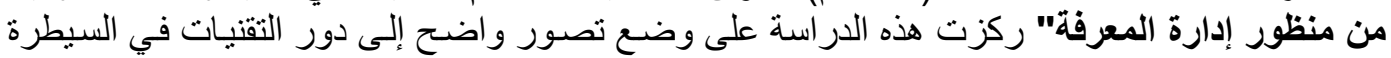

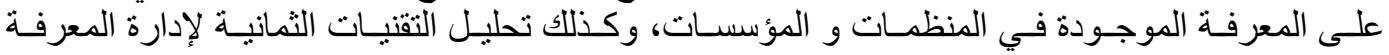

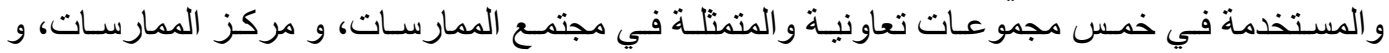

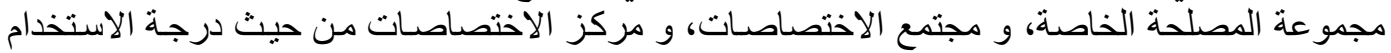

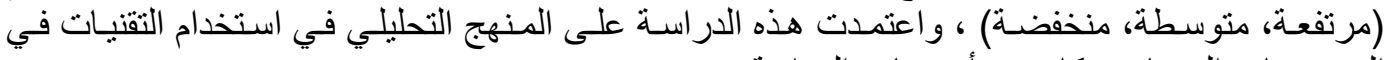

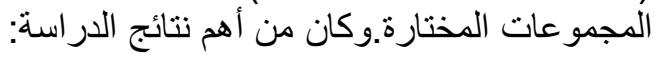

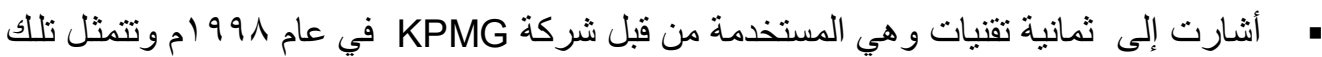

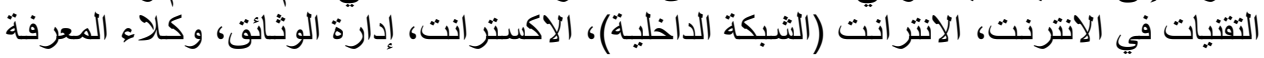

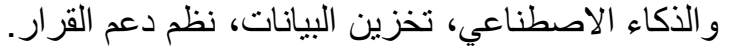




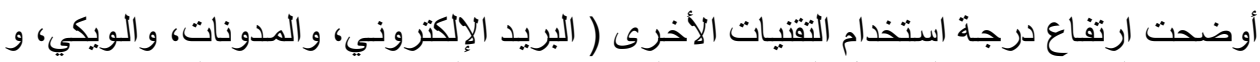

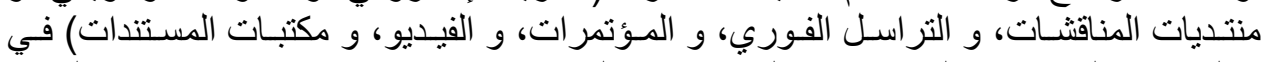

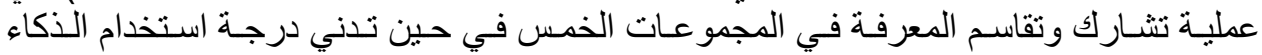

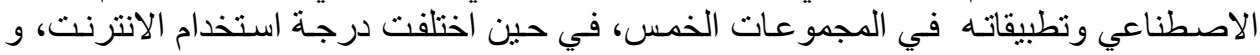

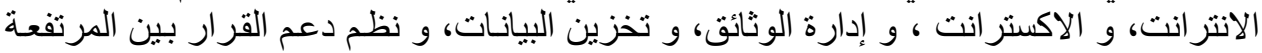

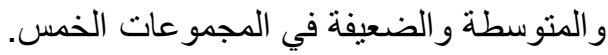

توصلت إلى أن مجمو عة سيجا (SIG) هي المجمو عة الوحيدة التي طبقت جميع التقنيات الثمانيـة

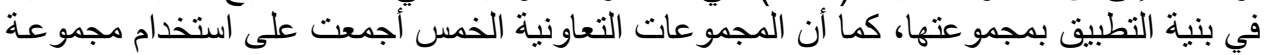

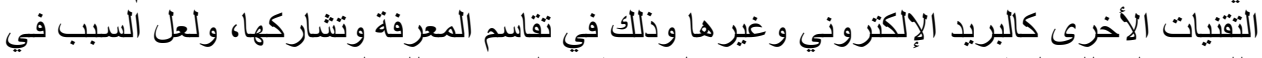

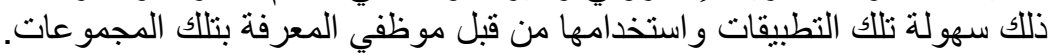

وكان من أهم التوصيات:

ضـرورة توفير البنيـة التحتيـة التقنيـة المناسبة لإدارة المعرفـة في المجموعات التعاونيـة والتي أغفل فئل

البعض منها استخدام تطبيقات تقنيات إدارة المعرفة في مجمو عتها( (O’Sullivan:2007, 223-230). و من خـلال مر اجعة هذه الدارسـة نلاحظ استخدام التقنيات في دورة حياة المعرفة في المجمو عات المختارة.

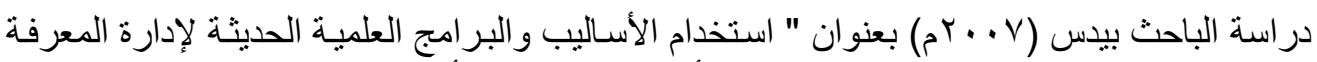

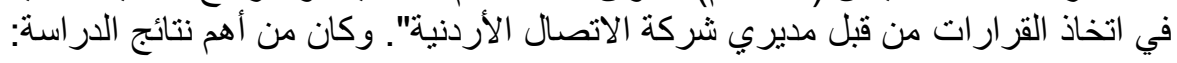
خلصت إلى أن تلك الثركات تستخدم الأسـاليب و البر امج الحديثة في إدارة المعرفة منل أنظمـة

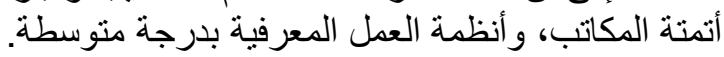

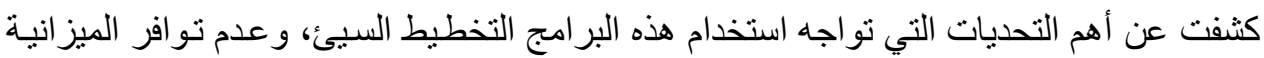

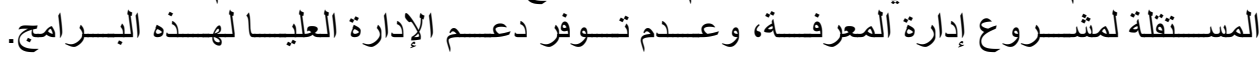

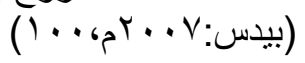

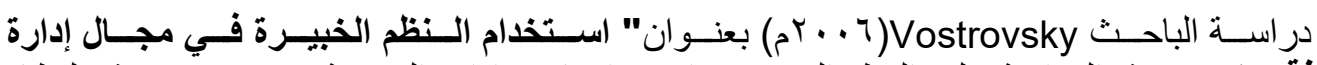

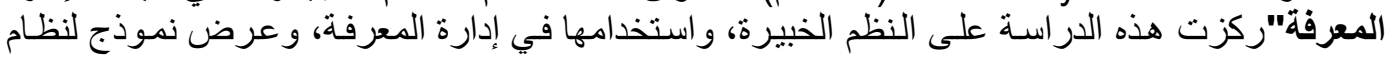

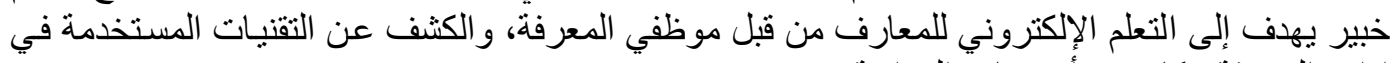

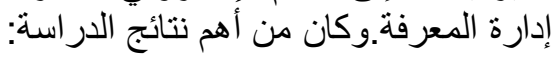

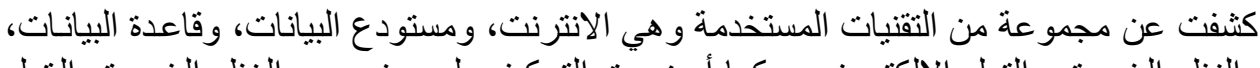

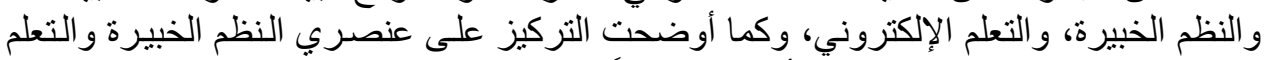

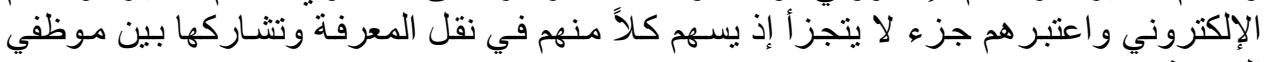
المعرفة.

أوضـحت أهميـة التعلم الإلكترونـي في مجـال إدارة المعرفـة فهو ذو فعاليـة وكفـاءة حيـث يتيح

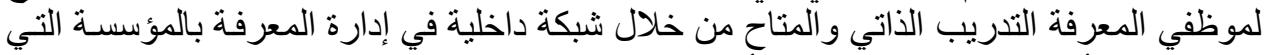

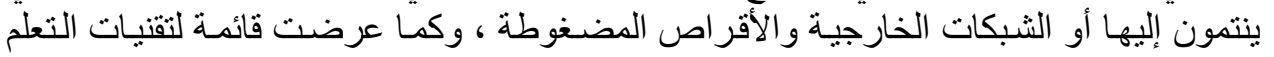
و التي تغطي مجمو عة واسعة من التطبيقات و العمليات بما في ذللك التعلم القائم على الكمبيوتر . 
كثفت عن عدة نمـاذج تمثل النظم الخبير، وهي نموذج أجز اء النظام الخبير، ونموذج الحلول

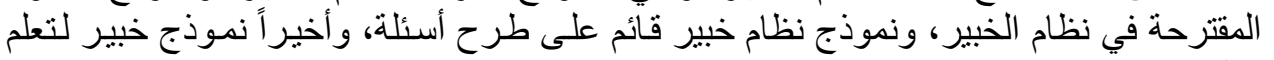
الإلكتروني.

أوضـحت شـمولية نظـام الخبير على أسـاليب بحث ذات كفـاءة عاليـة نظر اً لتعدد قو اعد البيانـات وقو اعد المعرفة.

أثـارت إلى العقبات التي تعترض تطبيق نظام الخبير القائم على التعلم الإلكتروني و المتمثلة في

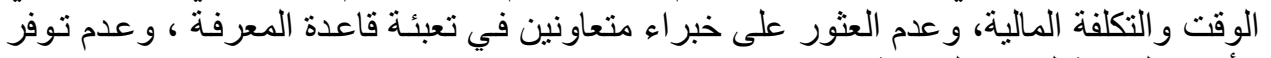
الأمن والحماية لقاعدة المعرفة.(Vostrovsky: 2006,451-455)

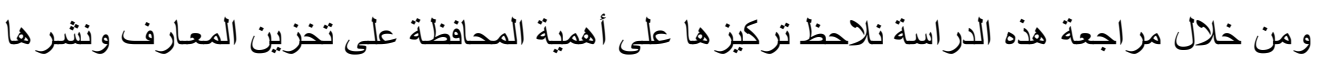

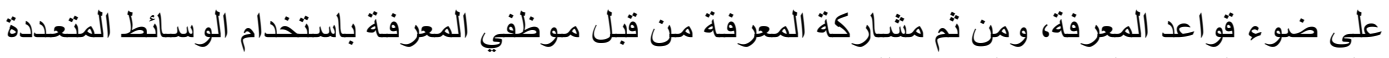

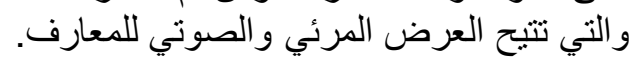

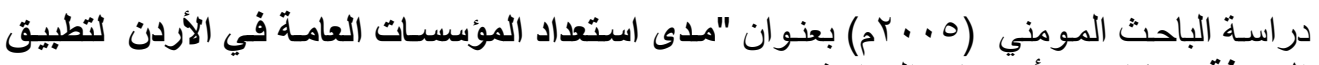

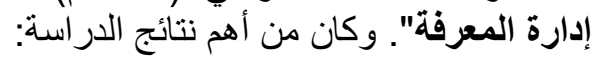

توصلت إلى توفر بنيـة تحتيـة لتقنيات المعلومـات والاتصـالات يمكن أن تسـاهم في إنجاح تطبيق

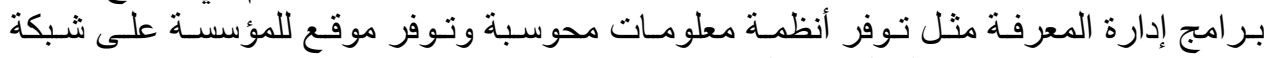
الإنترنت يساهم في إنجاز العمليات الإلكترونية.

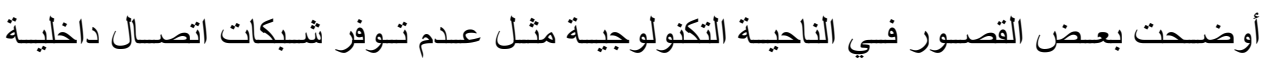

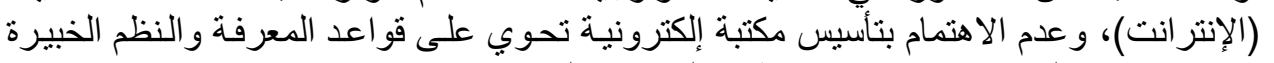

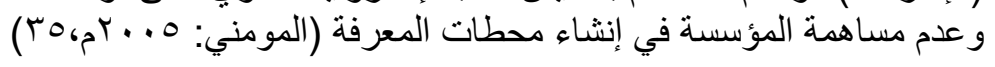

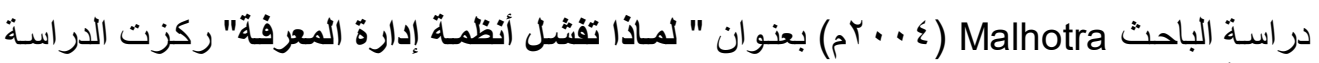

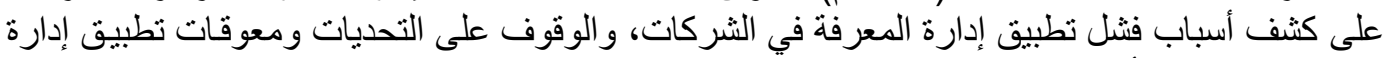
المعرفة. وكان من أهم نتائج الدر اسنة:

كثفت عن أكبر فثـل في إدارة المعرفة بالثركات الاقتصسادية الأمريكية مرجعـاً ذلك لتحديات

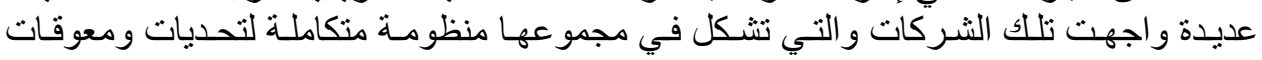

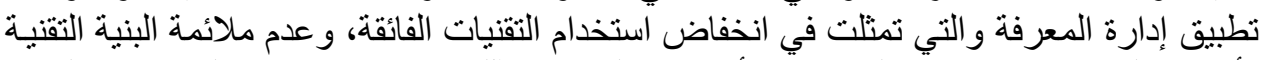

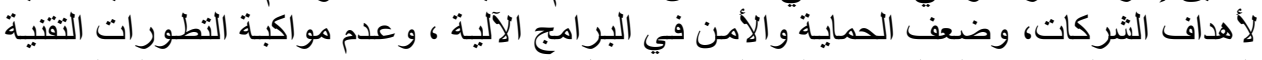

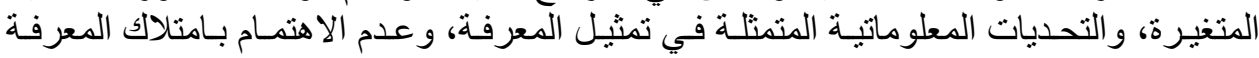

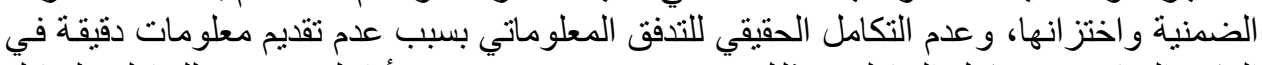

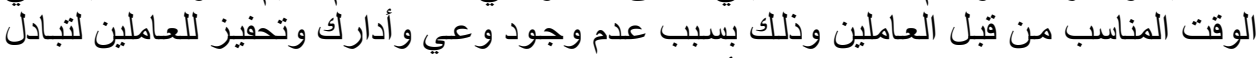

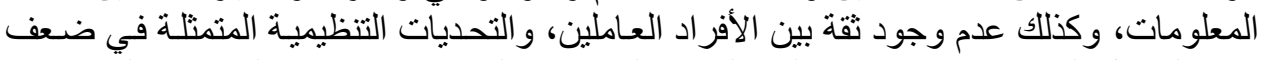

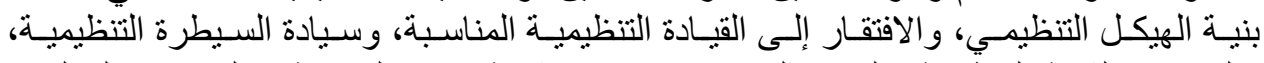

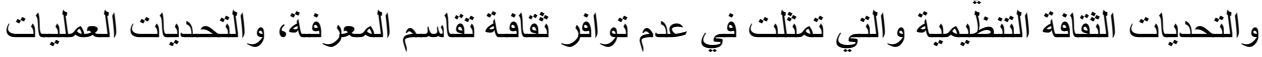

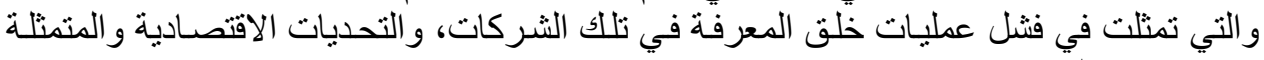

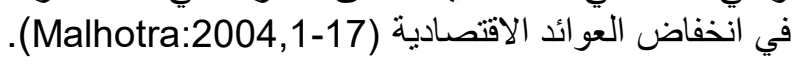




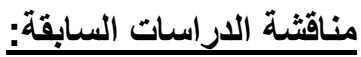

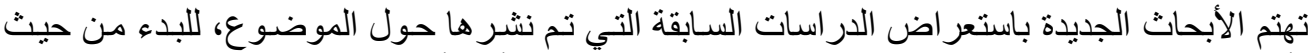

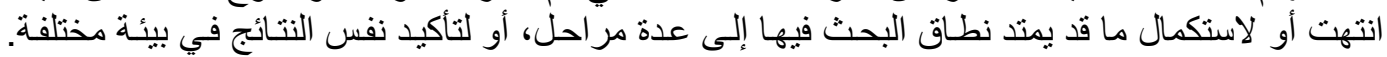

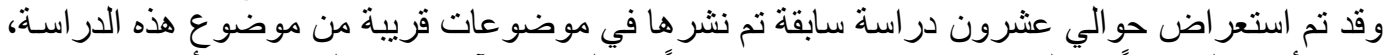

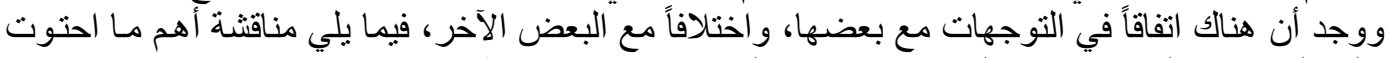
عليه الدراسات السابقة فيما يتعلق بتقنيات إدارة المعرفة وكيف تم توظيفها:

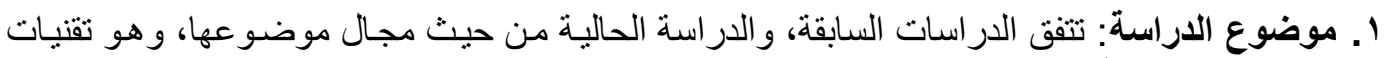

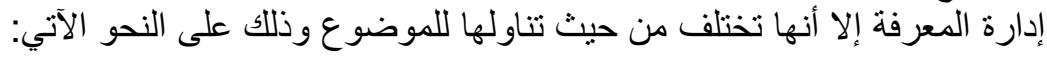

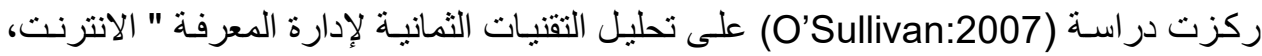

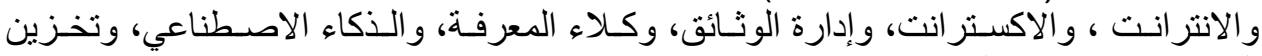
البيانات، ونظم دعم القرار".

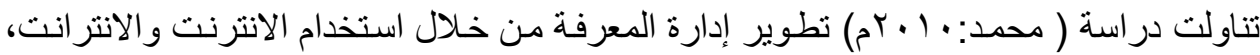
ومستودعات المعرفة ، و الثبكات الاجتماعية.

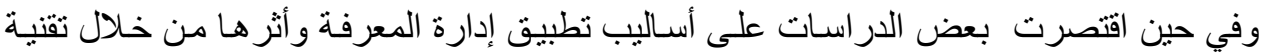

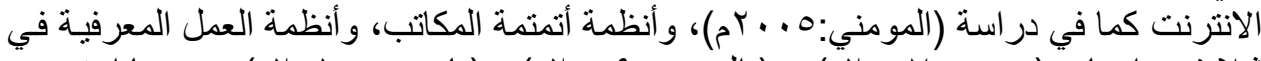

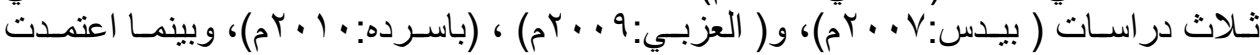

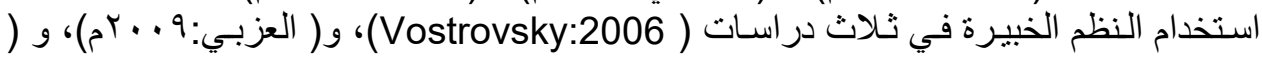

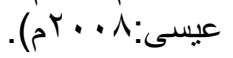

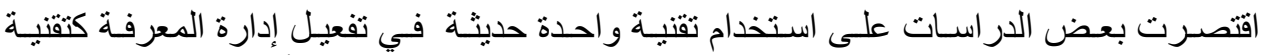

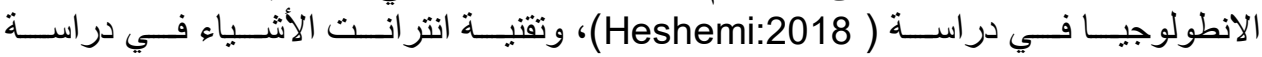

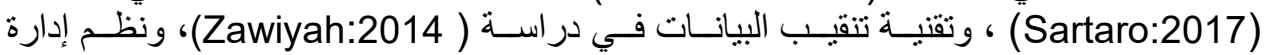
المعرفة كما في دراسة (2014) و (Agung:2014).

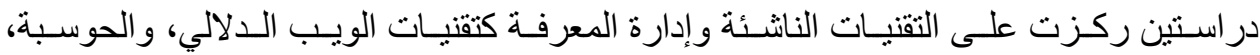

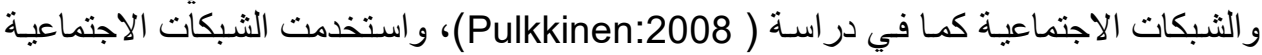

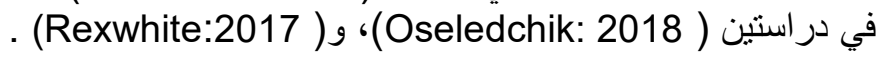

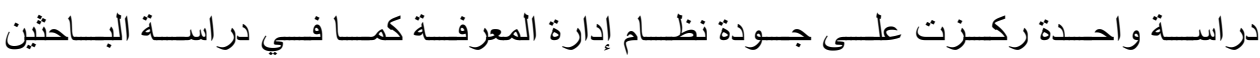
.(Jabar,Alnatsha:2014)

ركزت در اسة واحدة على معوقات تطبيق إدارة المعرفة كما في دراسة ( Malhotra:2004 ).

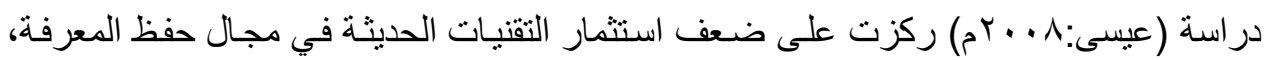
ونشر ها في مؤسسات التعليم العالي السعودية.

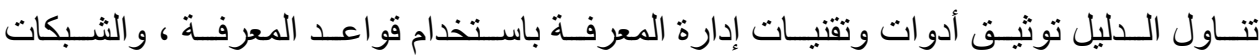

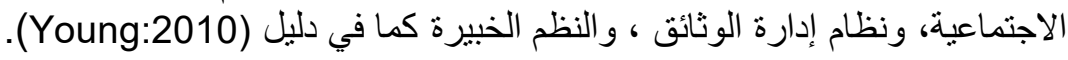

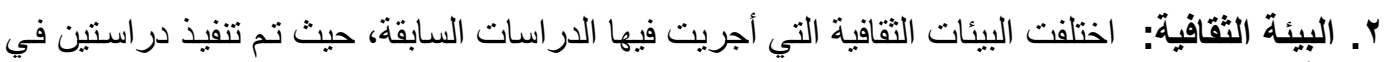

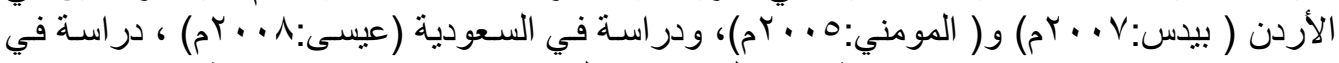

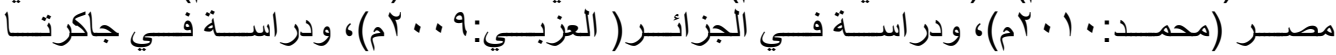

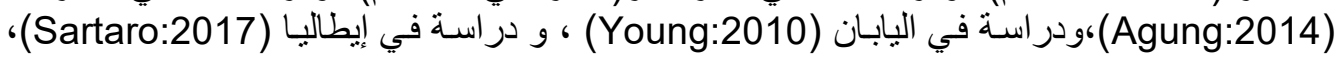




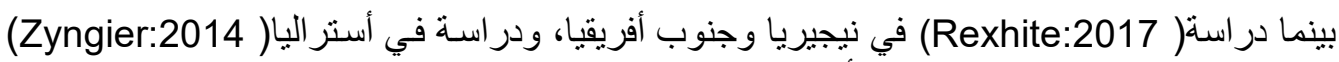
، ودراسة (Malhotra:2004 ) في أمريكا.

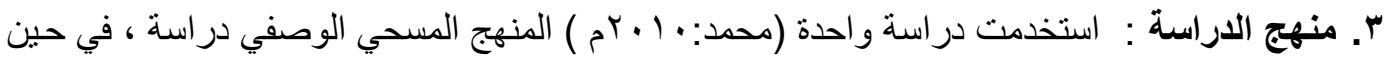

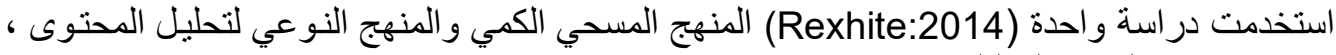

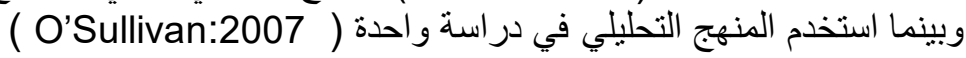

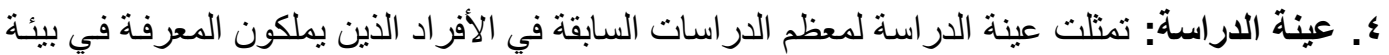

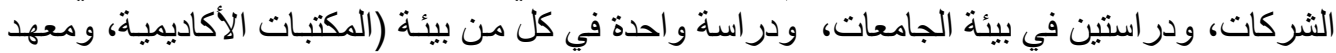

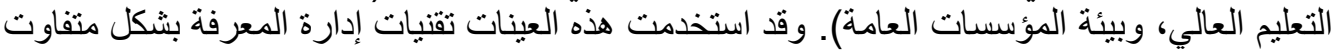
يتناسب مع أختلاف احتباجاتها.

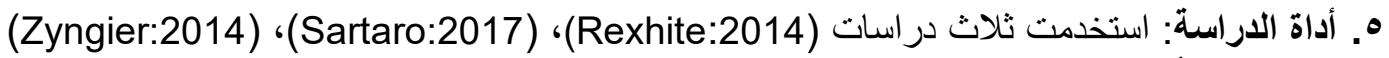

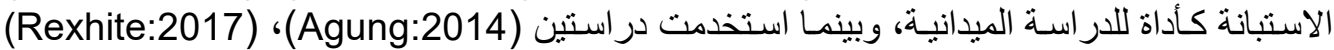
المقابلات الثخصية. وذلك لاستخلاص التقنيات المستخدمة في بيئات الدراسات.

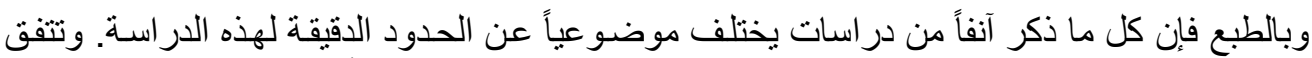

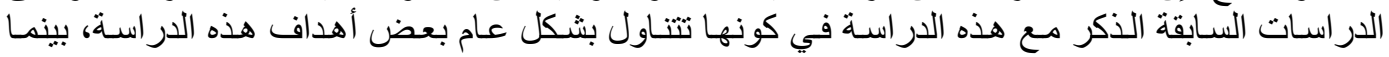

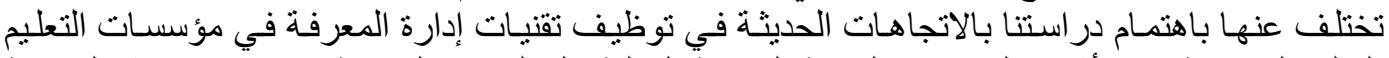

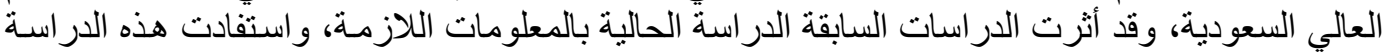

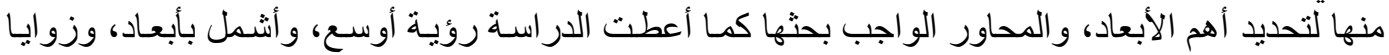
متباينة للموضوع.

\section{الإطار المعرفى المقترح لتوظيف تقتيات إدارة المعرفة في مؤسسات التعليم العالى السعودية:}

تعتبر مؤسسـات التعليم العالي السعودية مصدر اً ومورداً هامـاً للمعرفة، ليس بحكم توجهها البحثي

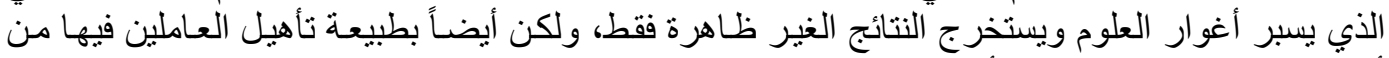

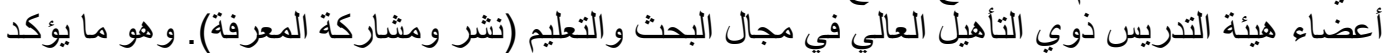

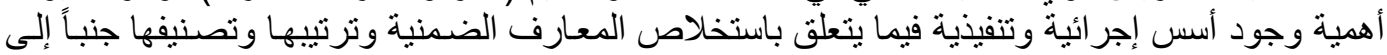

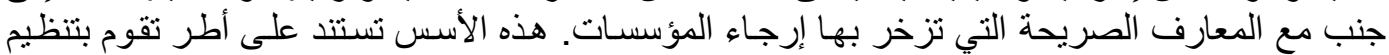

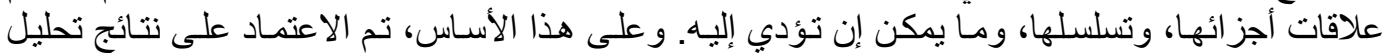

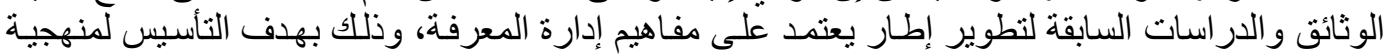

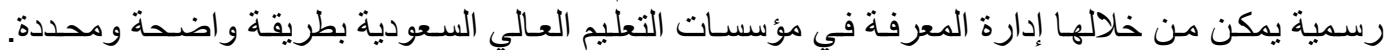

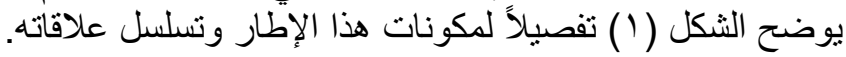




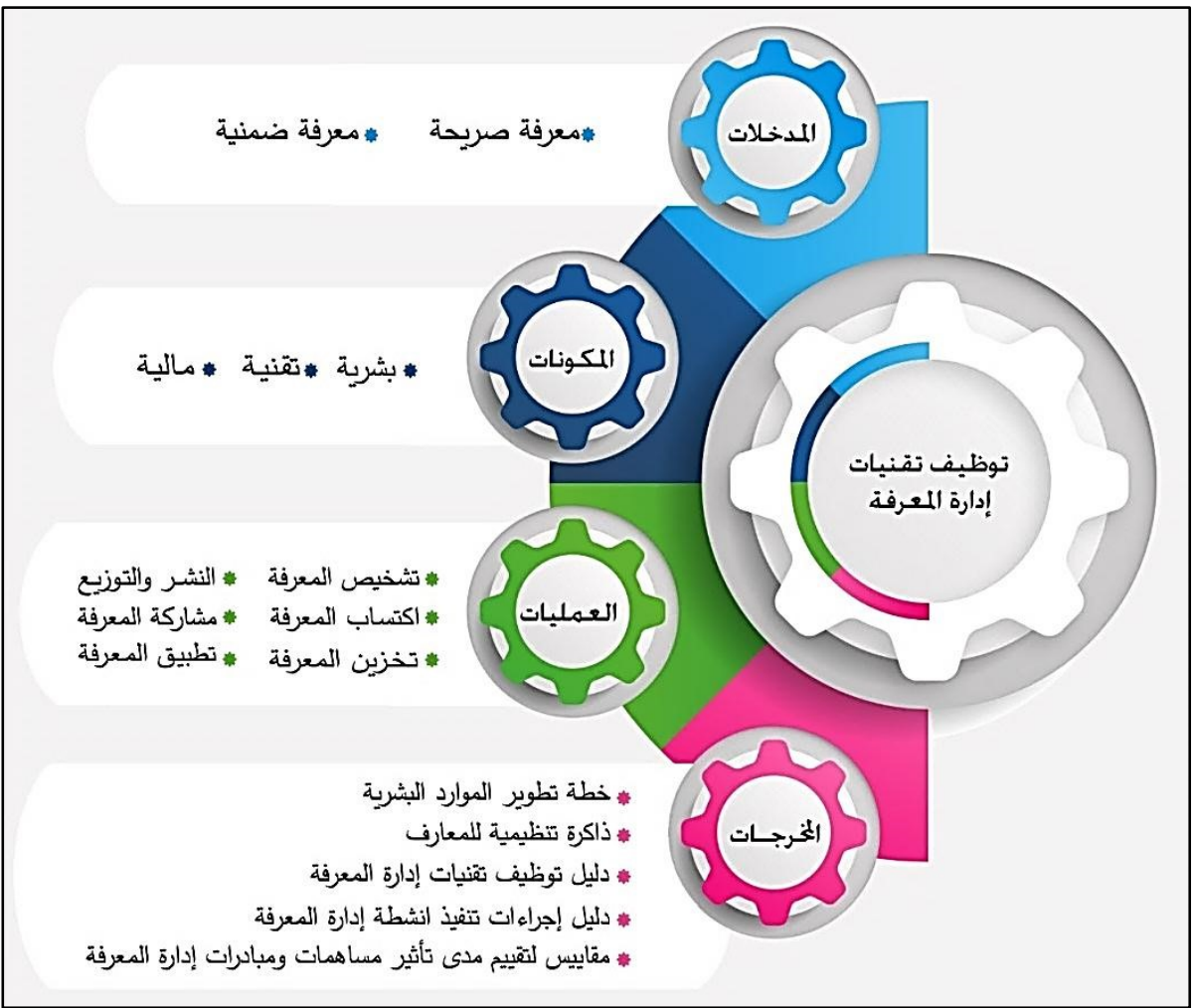

\section{شكل (1) إطار معرفي لتوظيف تقنيات إدارة المعرفة}

يتكون إطسار توظيف تقنيات إدارة المعرفة من أربعة تصنيفات ( المدخلات، المكونـات، العمليات، المخرجات)، و هي على النحو الآتي: أولاً: المدخلات: أن

تتكون المدخلات من أهم التصنيفات البارزة للمعرفة و هذا مـا ذكره نوناكا الذي صنفها إلى نوعين رئيسين هما:

\section{: Tacit Knowledge المعرفة الضمنية}

هي مصطلح يشير إلى المعرفة الموجودة في عقول الأفر اد، و المكتسبة مـن خـلال تر اكم خبرات

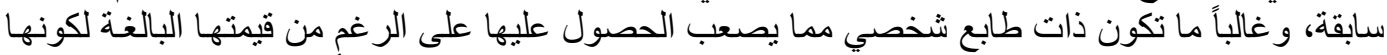

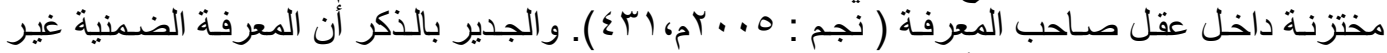

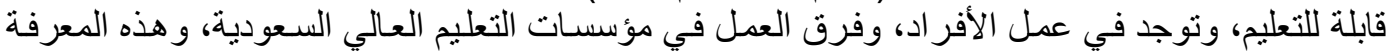

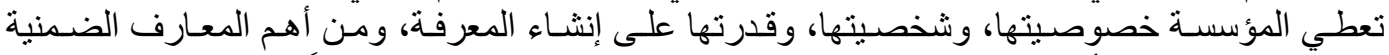

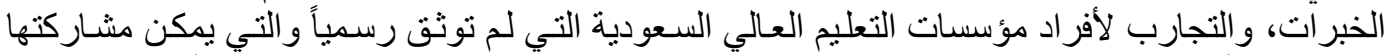

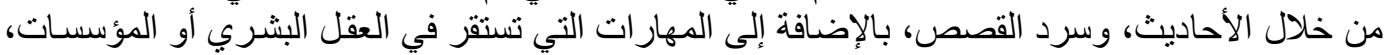
و المكتسبة من خلال نر اكم خبرات سابقة (Daft: 2001,259). 
و ون هنا نلاحظ إن مشاركة المعرفة الضمنية يساعد في التقليل من إمكانيـة فقدانها، وتمكن من إعـادة إنهاة

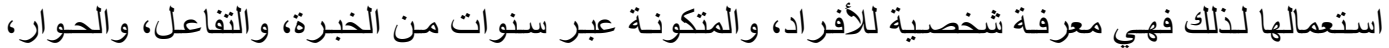
و التطبيق.

ولقد أشـار الأدب المنشور لضرورة تو افر شرطين أساسين لمشـاركة المعرفة الضـنية، وهي: أولاً

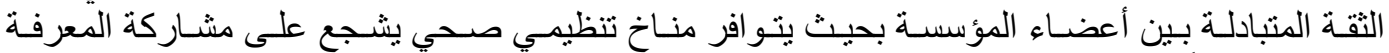
الضمنية، وثانياً وجود تفاعل شخصي غير رسمي بين أفراد المؤسسة، وذللك لأن مشناركة المعرفة الضمنية يكون أفضل في الأوضاع غير الرسمية منها من الرسمية (Alwis: 2004,375).

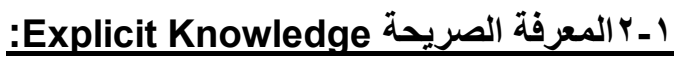

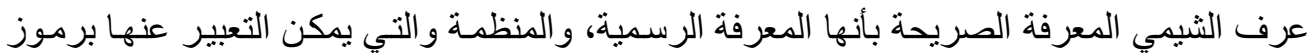

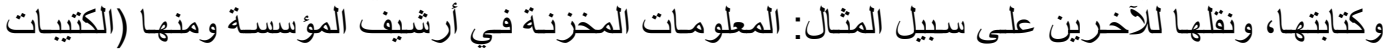

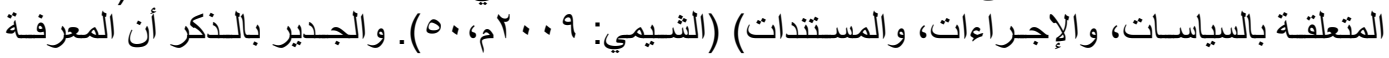

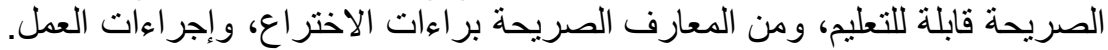

ثثاتياً:المكونات:

يتكون الإطار المقترح من ثلاث مكونات رئيسية هي ( التقنيات، الموارد البشرية، الموارد المالية)، وهي على النحو الآتي:

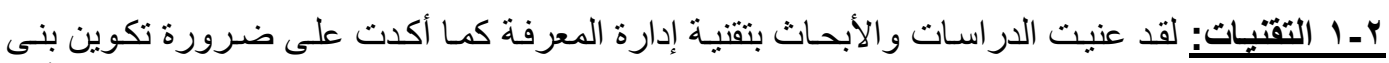

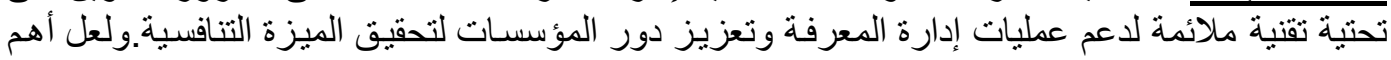

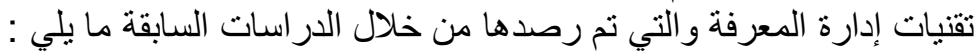

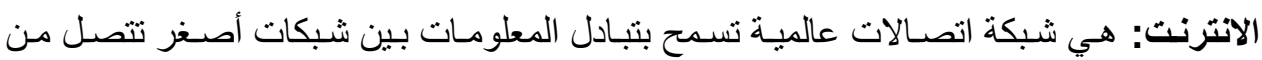

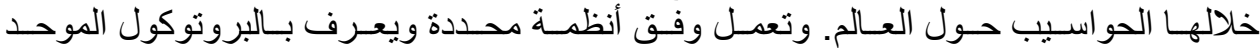
و هو بروتوكول إنترنت. • الانترانتة: هـي شـبكة داخليـة تتـاح لمـوظفي المعرفـة عدد مـن الخدمات كمـا تتيح التشـارك في الاكستر اتت: هي امتداد للإنتر انت الخاص بمؤسسة معينة يتم إنشاؤ ها من أجل مستخدمين معينين

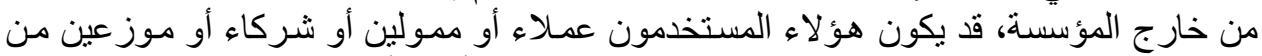

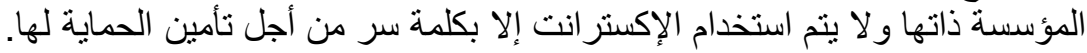

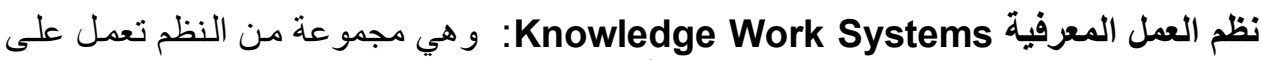

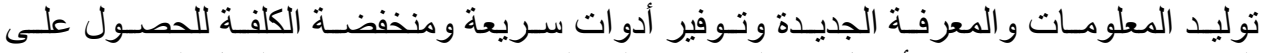

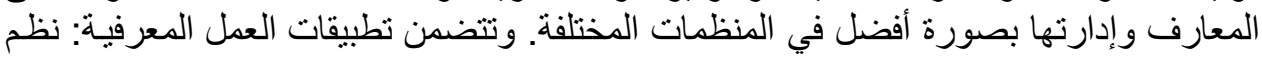

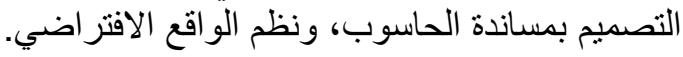
نظم أتمتـة المكتب Automation Office Systems: تسـتخدم هذه النظم لأتمتة المهام

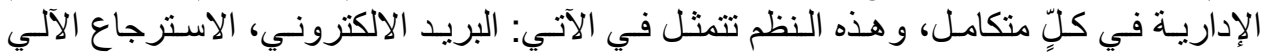

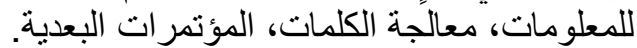




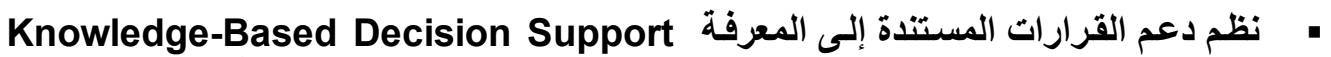
: Systems وهي تمكن المدير من اتخاذ قرار الت ذات ذات مدى أوسع وأكثر تعقيداً. نظم الذكاء الاصطناعي Artificial Intelligence Systems: هو جهد لتطوير نظم مستندة

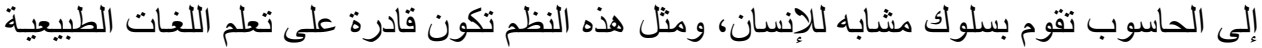

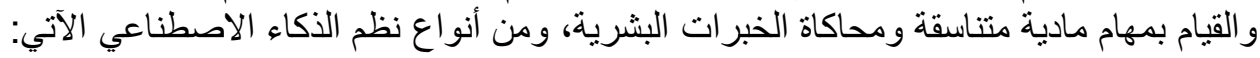

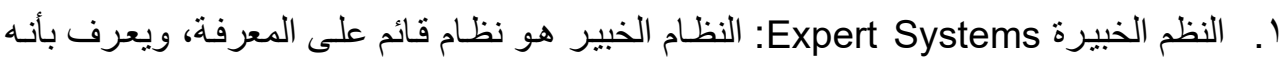

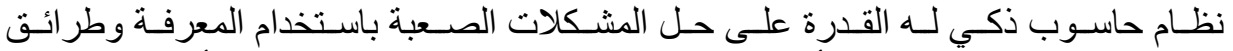

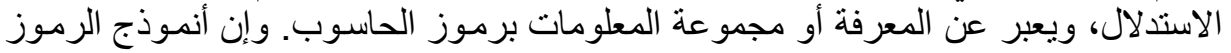

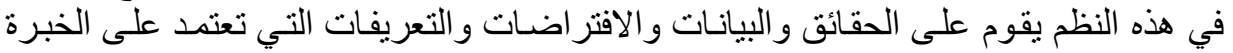
المجمعة ، و على معرفة الخبراء البشر.

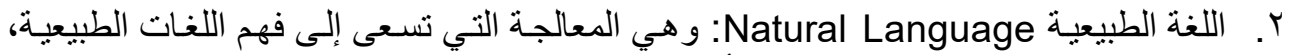

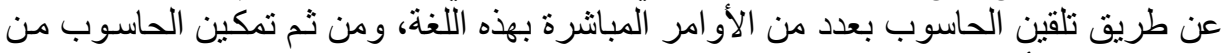

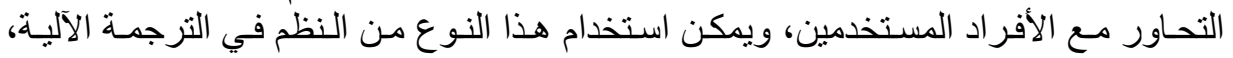
والخلاصات، والبحث عن نصوص ثبت المر اجع.

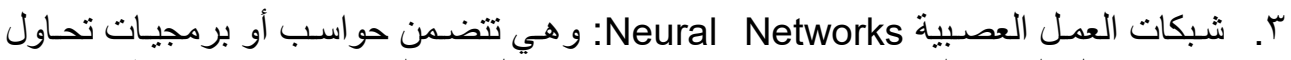

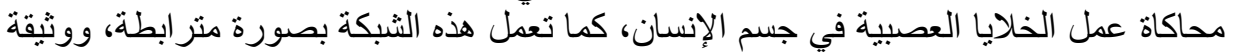

$$
\text { ، ومتوازية. }
$$

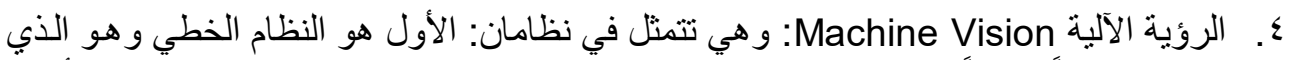

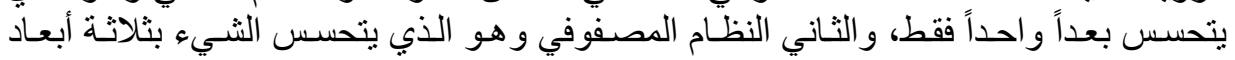

$$
\text { (المجسم). }
$$

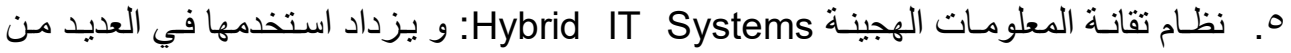

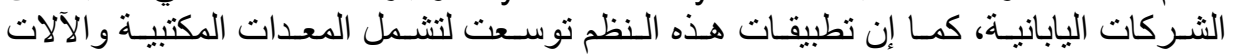

الصناعية (Turban: 1998,214-215)

الحوسبة السحابية Cloud Computing:عبارة عن نموذج لتمكين مستعمل الثبكة من النفاذ

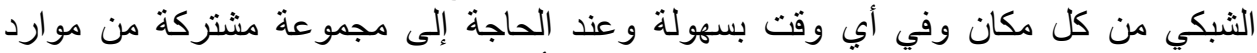

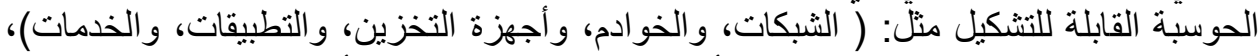

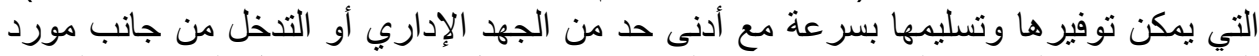

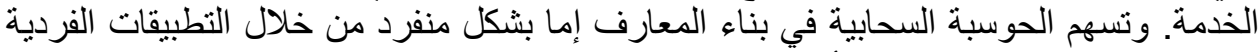

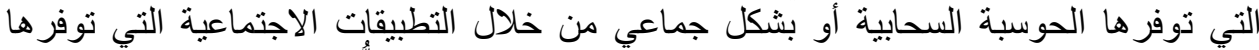

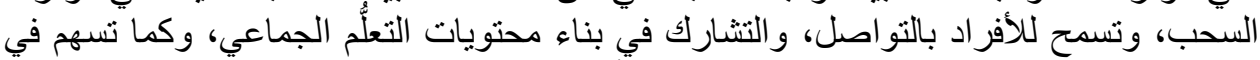

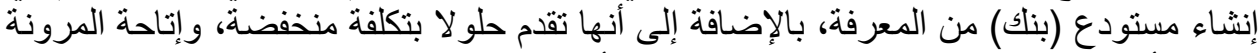

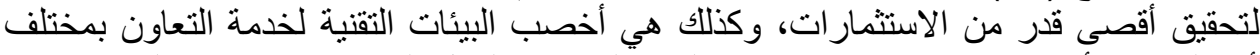

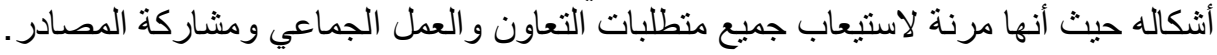

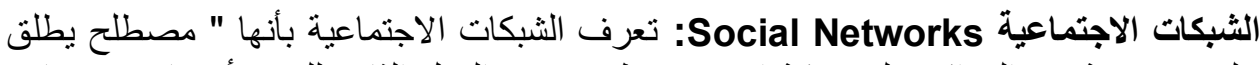

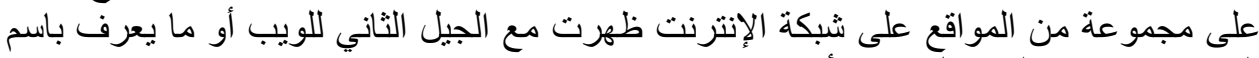

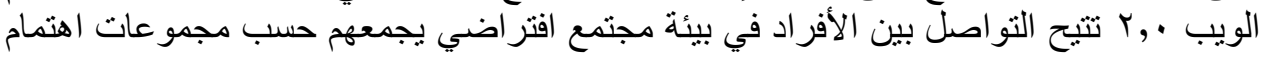




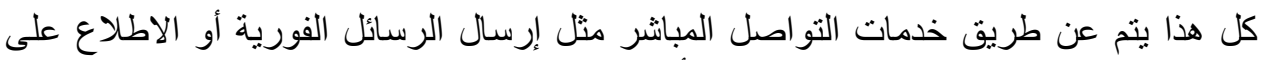

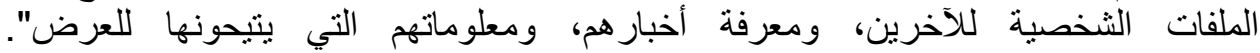

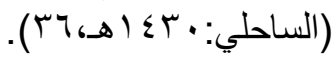

المستودعات الرقمية Digital repository: هي قاعدة معلومات مناحة عبر الإنترنت قد تنشأ

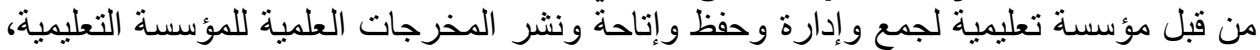

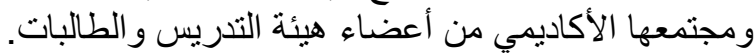
قواعد البيانـات Base Data: هي بنـاء ذو هيكليـة محددة يضـم بيانـات مخزنـة الكترونيـا ويتم ضمن نطاقه السيطرة على البيانات و الوصول إلبها من خلاعل حواسيب. تنقيب البيانـات Data mining: عملية اكتشاف المعرفة في قو اعد البيانات عن طريت تحديد الأنماط والاتجاهات في البيانات التي تم جمعها باستخدام طرق مختلفة مثنل : التصنيف أو أو التحليل

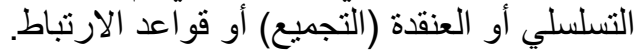

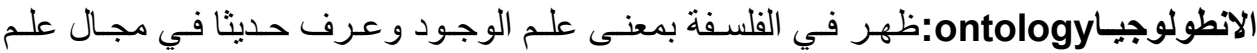

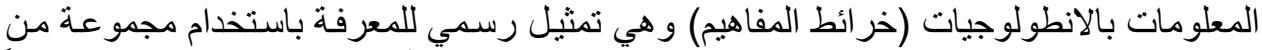

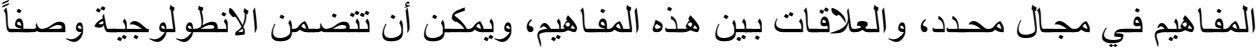

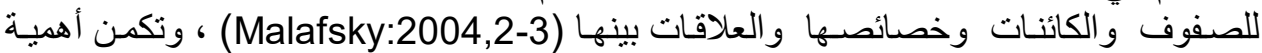

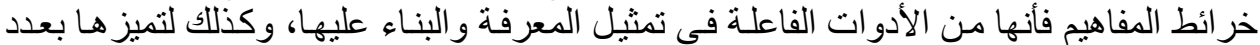

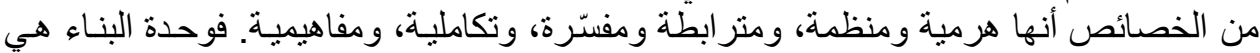
المفاهيم.

انترانت الأشياء Internet of Things:هي الجيل الجديد من الإنترنت (الثبكة) الذي يتيح

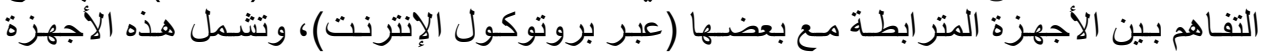

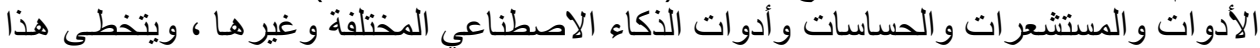

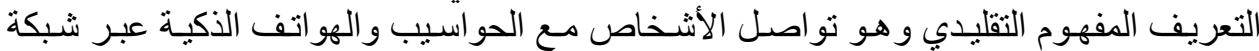

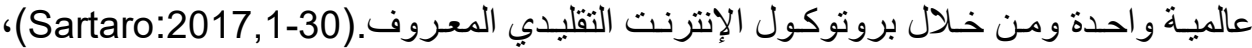

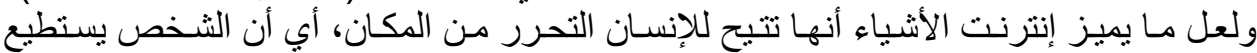

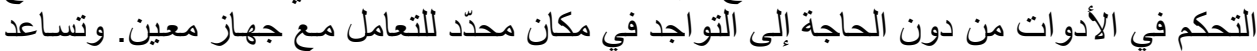

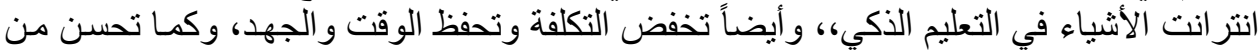

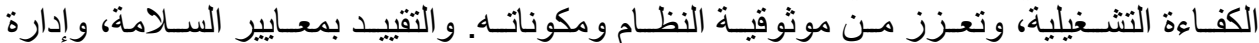

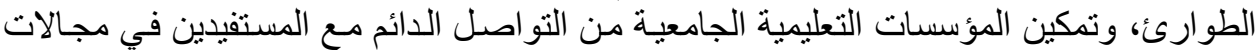

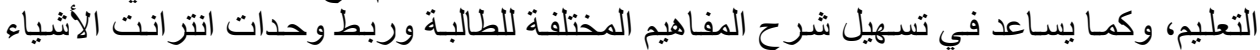
بالو اقع المر اد محاكاته.

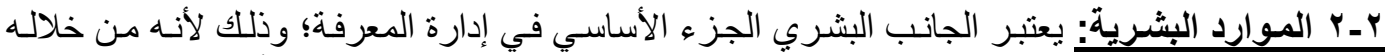

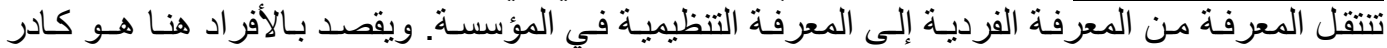

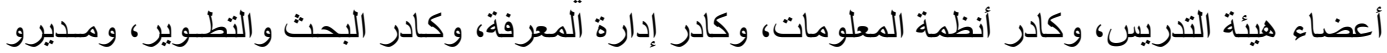

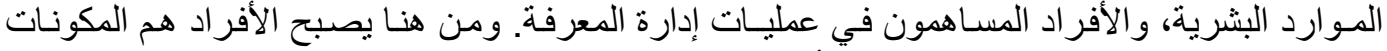

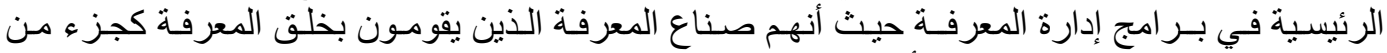

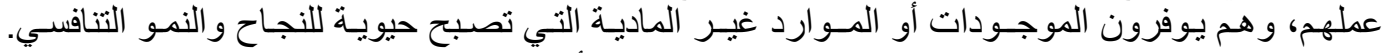

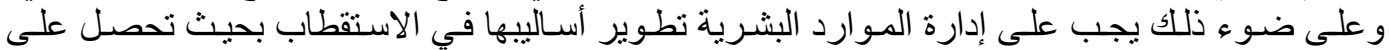

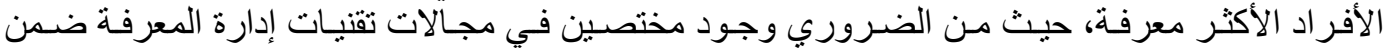




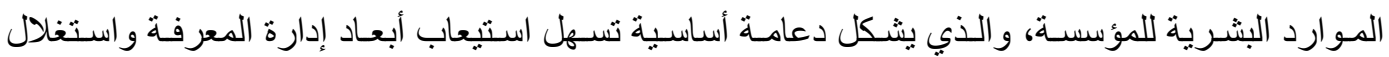

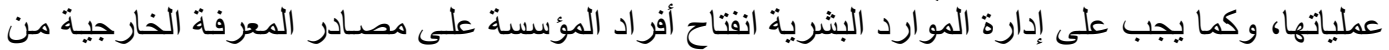

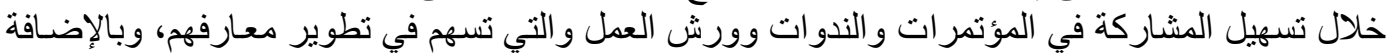

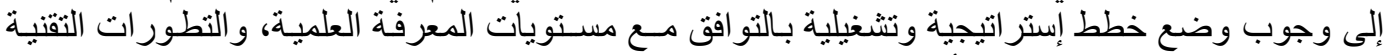
في مجالات التعليم و التدريب و والتأهيـل وتنميـة المـوارد البشرية.

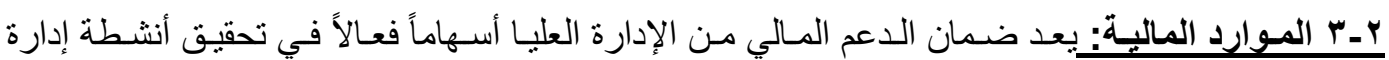

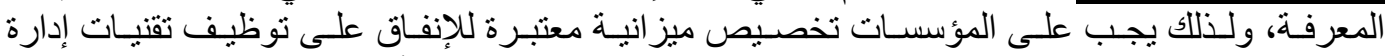

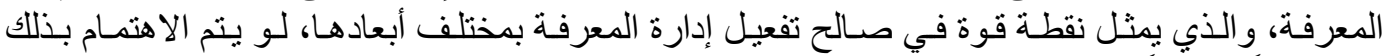
استر اتيجياً و تنفيذياً.

ثالثثاً: العملياث

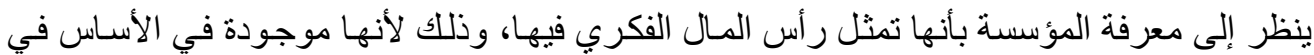

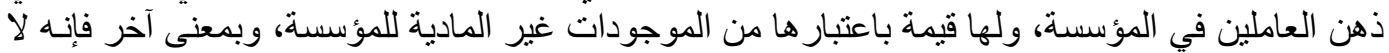

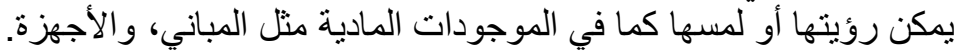

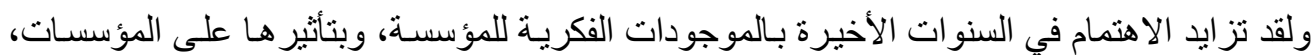

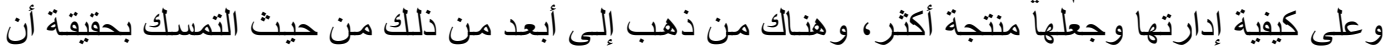

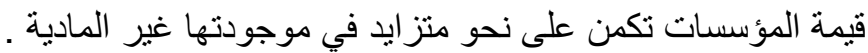

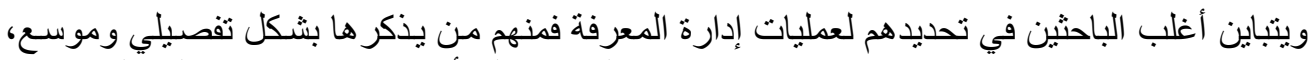

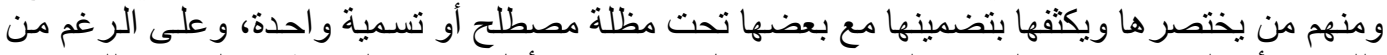

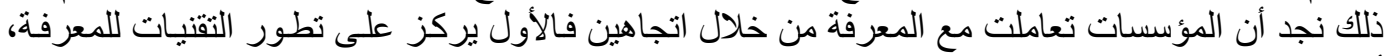

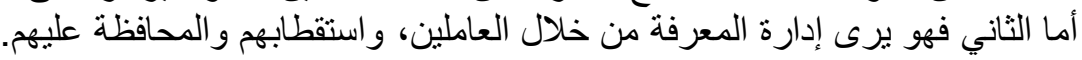

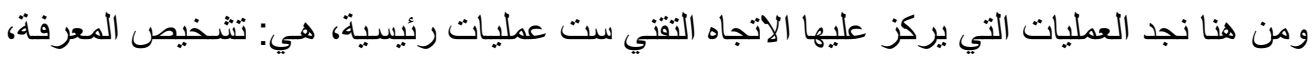

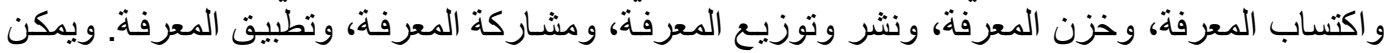
شرح آليات استخدام تللك التقنيات الرئيسة، والفرعية ونئ في عمليات إدارة المعرفة على النحو الآتي:

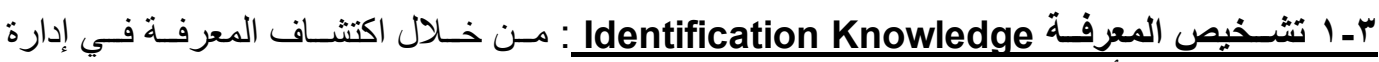

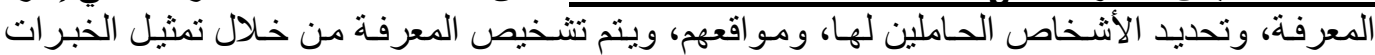

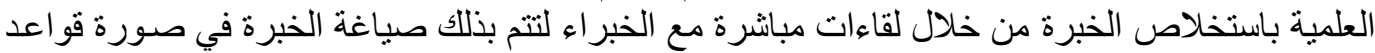
بيانات.

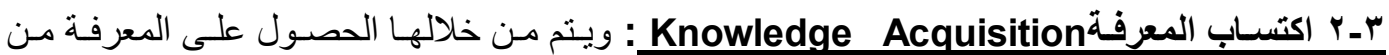

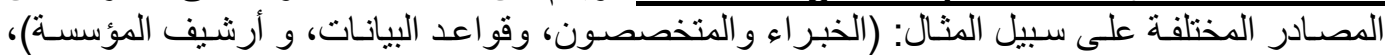

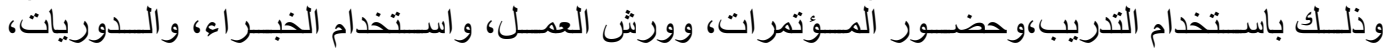

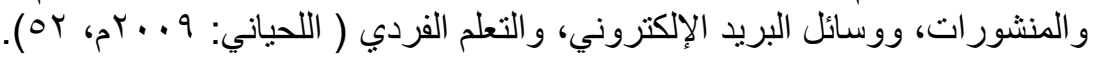

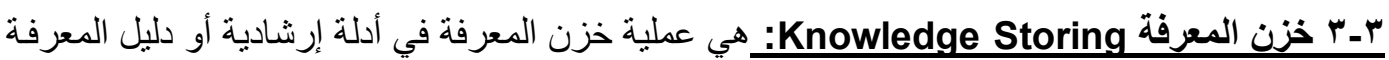

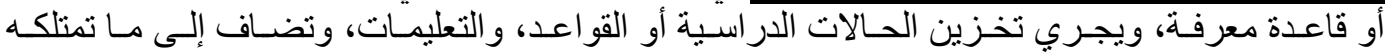

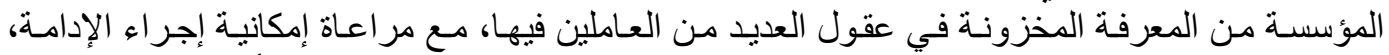

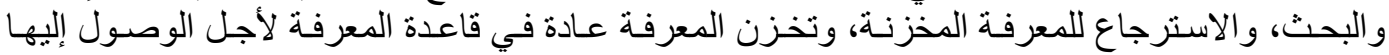


بسر عة حيث تتاح من خلال الشبكة الداخلية الإنترانت لموظفي المعرفة عدداً من الخدمات، كما تتيح لهم ألها

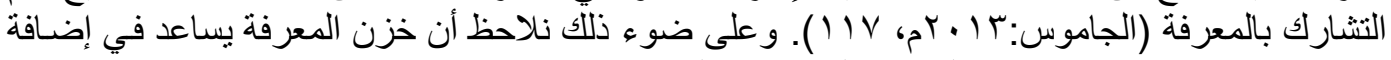

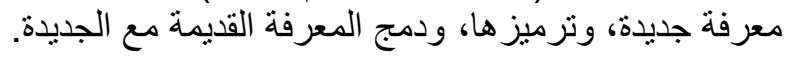

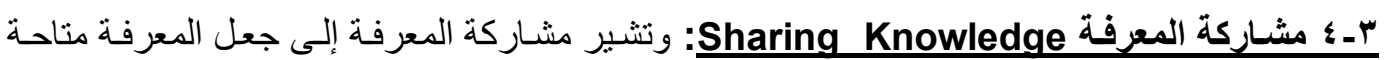

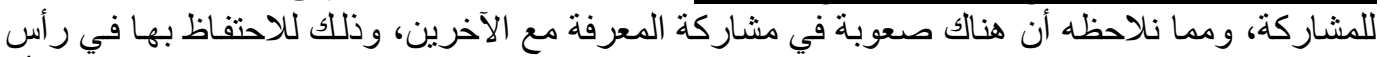

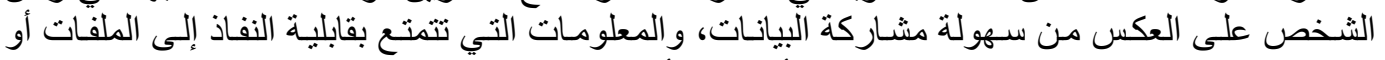

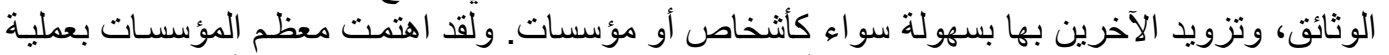

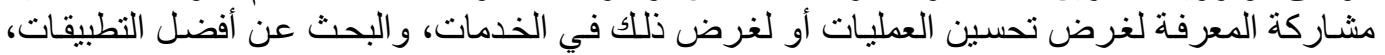

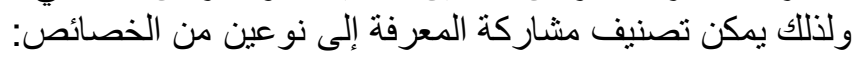

- المشاركة الجماعية: كوسيلة لمشاركة الأفكار، وطريقة للتدفق الحر للمعرفة بأكثر مما تسمح بـهـ

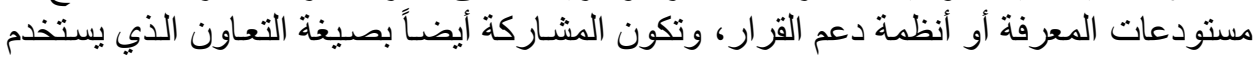

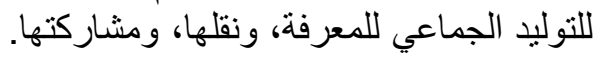
المشاركة الفردية: تمنلك معظم المؤسسات شخص أو أكثر من (الخبر اء) ممن يمتلكون المعرفة

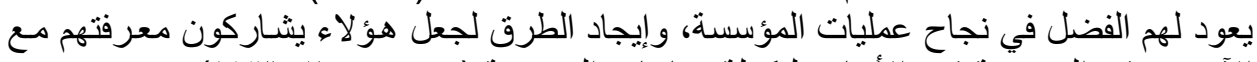

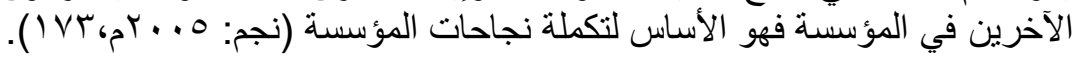

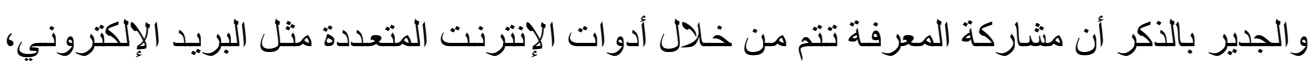

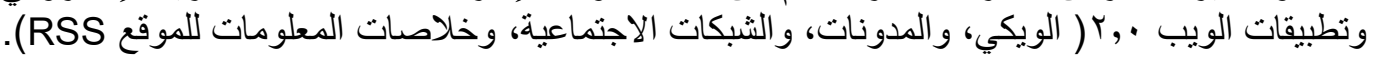

بـه نشر وتوزيـع المعرفة Distribution and Deployment Knowledge: توفير المعرفة

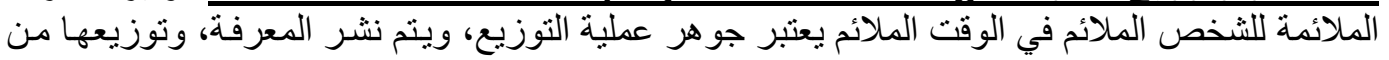

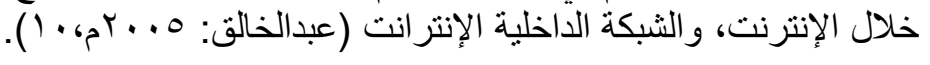

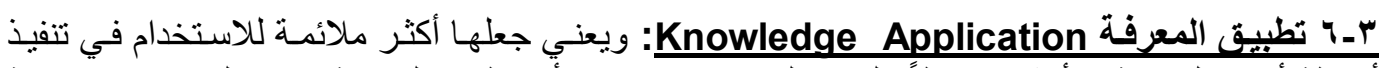

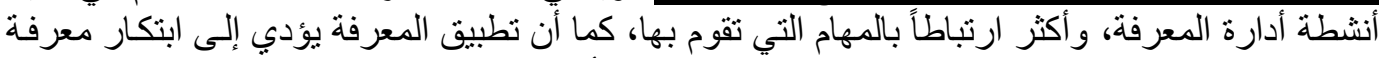

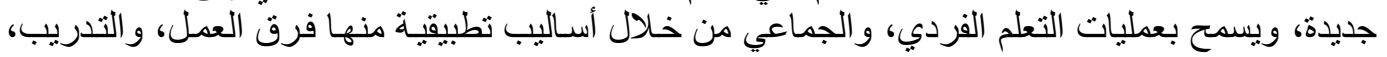

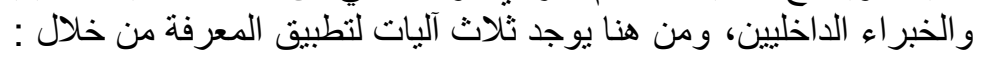

ـ مجمو عة محددة من القو اعد، والإجراءات، و التعليمات التي يتم وضعها لتحويل المعرفة الضمنية

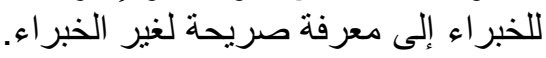

- وضع أنماط للأداء، ومو اصفات للعمليات تسمح للأفر اد بتطبيق ودمج معرفتهم المتخصصـة دون الحاجة إلى الاتصال بالآخرين.

بناء فريق عمل متخصص في مهام محددة ذاتياً بحيث يتم استخدامها في مواقف تكون فيها المهام

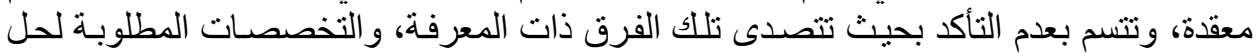
المشكلات. ويتم تطبيق المعرفة من خلال الاعتماد على الأنظمة التقنية الرئيسية، و الفرعية والتي تشمل ما يأتي:

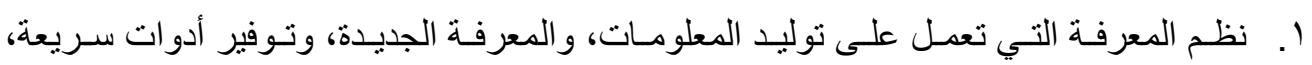
ومنخفضة الكلفة للحصول على المعارف ولى ولئل إدارتها. 
Y. نظم إدارة الوثائق و التي تمكن من إدارة ونشر المعلومات، و المعرفة.

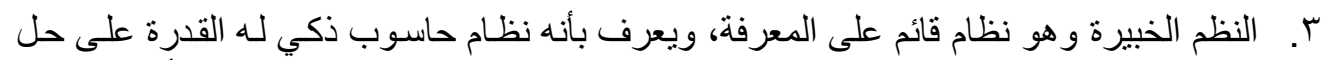

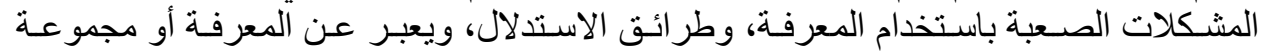

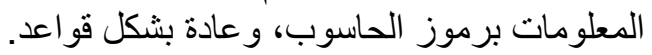

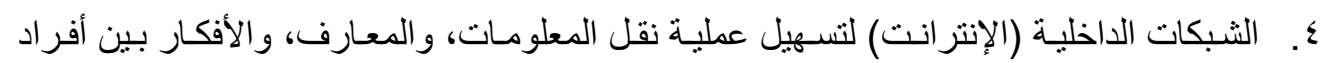

مؤسسات التعليم العالي السعودية.

ه.الشبكات الاجتماعية و التي تسهم في مشاركة المعرفة الصريحة، و الضمنية للأفر اد، ومؤسسات التعليم العالي السعودية.

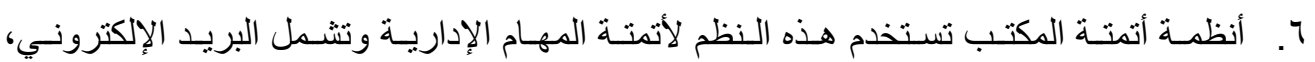
والاسترجاع الآلي للمعلومات، ومعالجة الكلمات، و المؤتمر ات التهات البعدية.

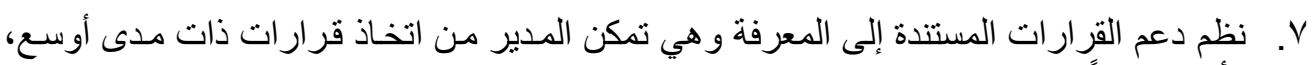

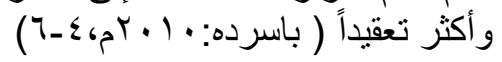

والجدير بالذكر أن تطبيت إدارة المعرفة يتطلب إضـافة لتقتيات المعلومـات المناسبة إلى تهيئة بيئة

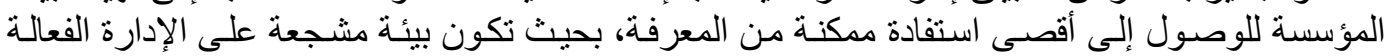

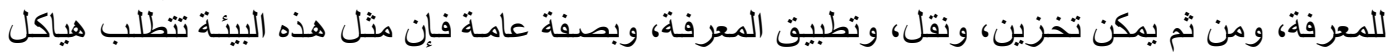

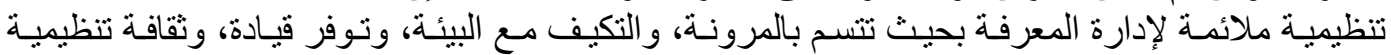

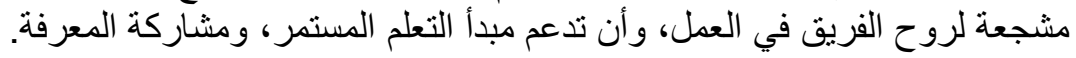

رابعاً: المخرجات تضمن التصور المقترح عدداً من المخرجات وهي على النحو الآتي:

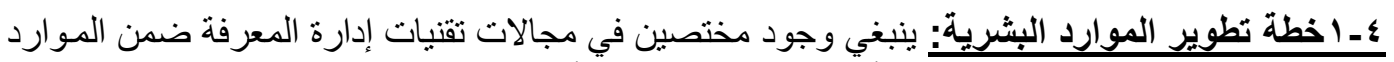

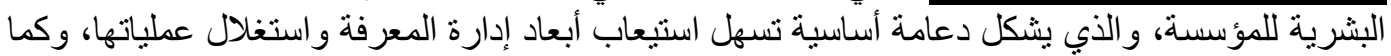

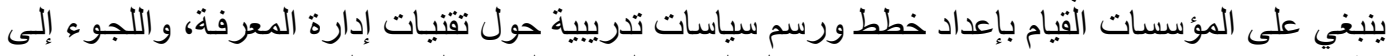

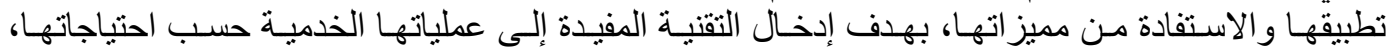

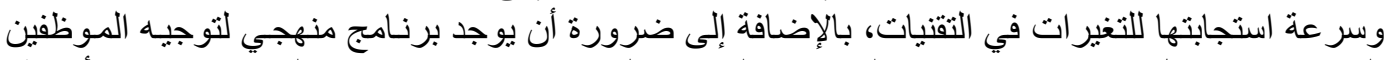

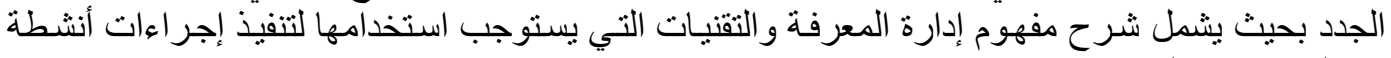
وعمليات إدارة المعرفة.

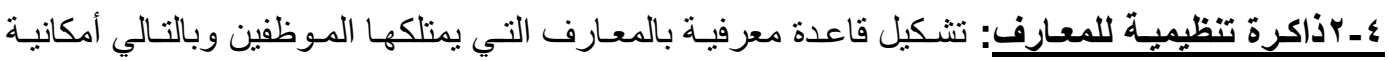

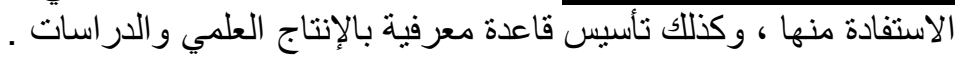

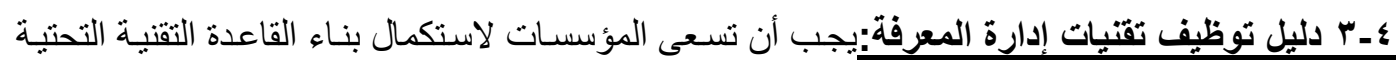

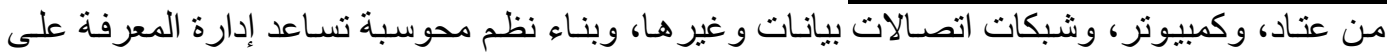

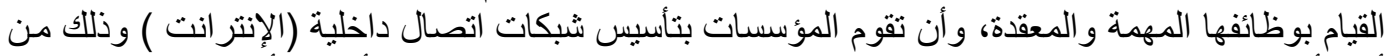

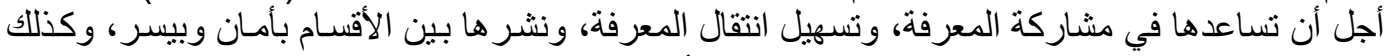

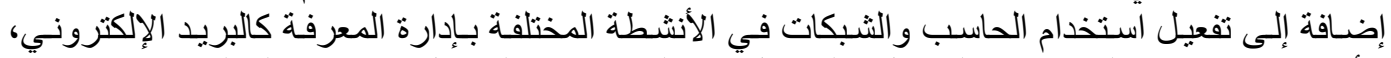

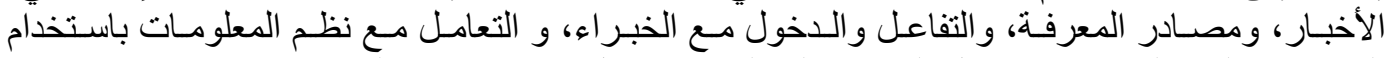
الحاسب، وإلز ام الموظفين بتسجيل الدروس المتعلمة من خلال تتفيذ وظائفهم اليومية. 
عـ ـ دليل إجراءات تنفيذ أنشطة إدارة المعرفة: يجب على المؤسسات أن تضع خطط توضسح كيفية أتمتة

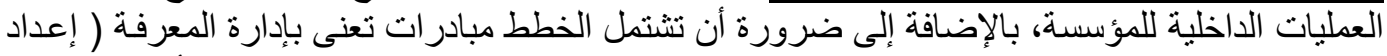

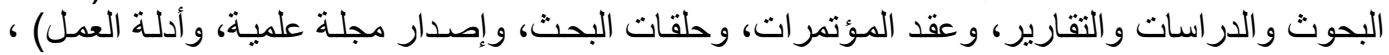

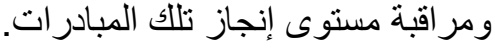

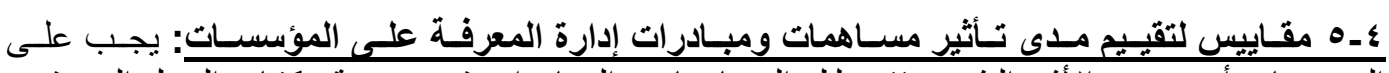

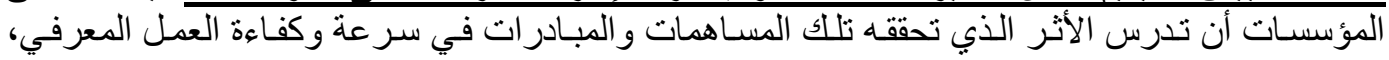

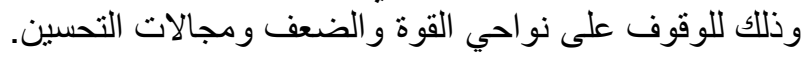

الأتخائجج:

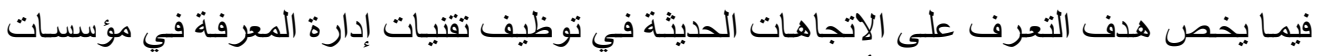

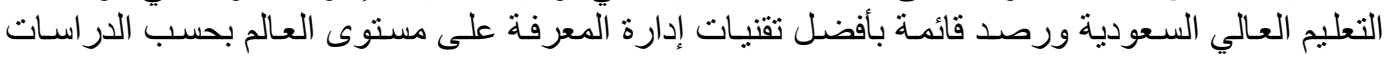

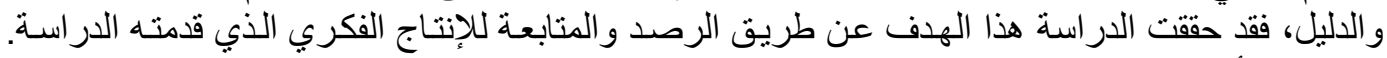

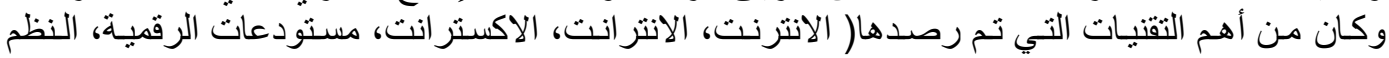

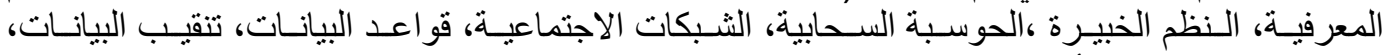
الانطولوجيا، انترنت الأشياء) والتي يمكن توظيفها في عمليات إدارة المعرفة.

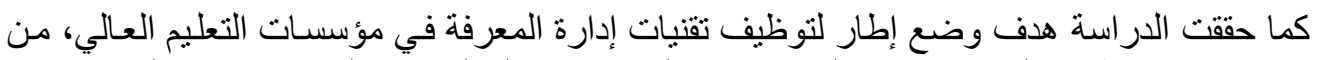

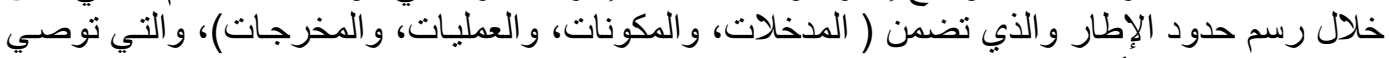

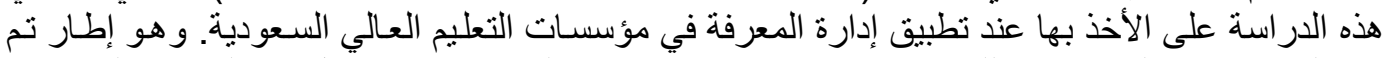

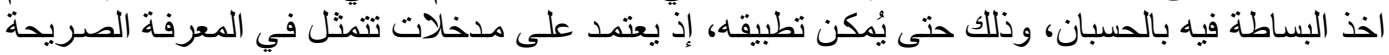

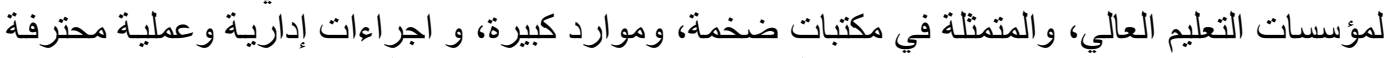

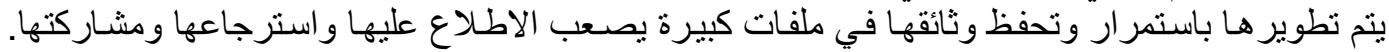

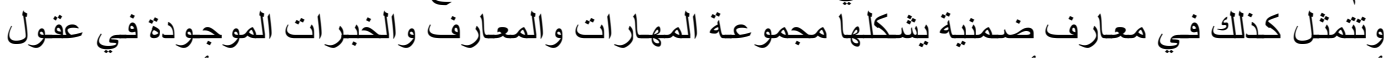

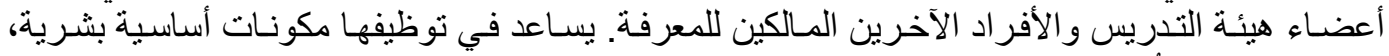

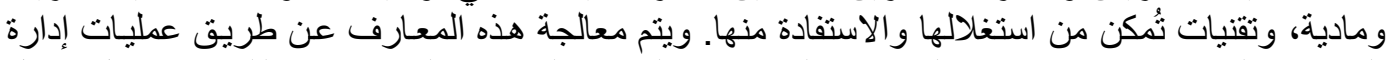

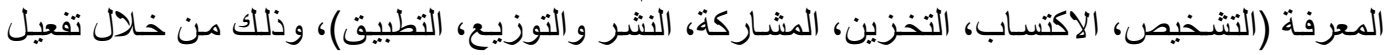

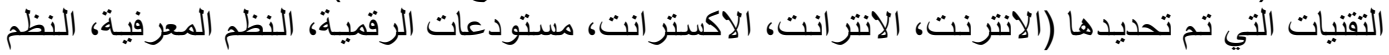

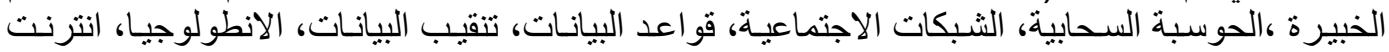

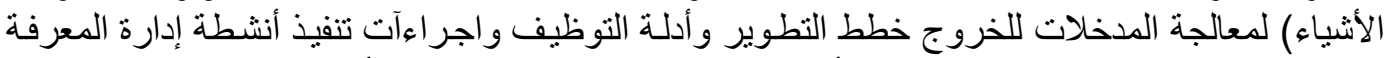

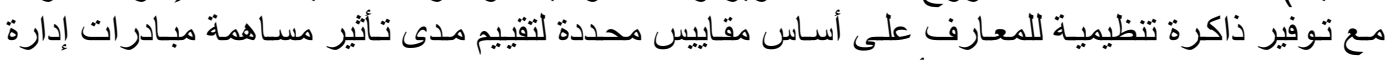

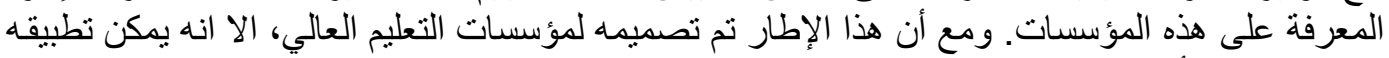

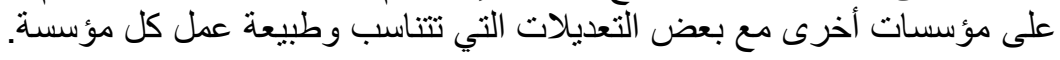

التوصيات:

ا ـ ضرورة تحسين كفـاءة وفعاليـة تقنيات إدارة المعرفة الموجودة في كل مؤسسـات التعليم العسالي السعودية.

Y. . التأكيد على إيجاد أنظمة حماية إلكترونية على الأجهزة و البر امج والبيانات. r. ب. بجب تقديم حو افز مادية ومعنوية للموظفين الذين يسهون في نقل ومشاركة المعرفة. 
ع. تيسبر التعليم واستثمار الخبرات والمعرفة المتر اكمـة لدى الأفر اد من خـلال استخدام التقنيات الحديثة.

○. ضرورة الاستفادة من انترانت الأشياء في خدمـة البحث العلمي، وتكوين مجموعات للتعـاون

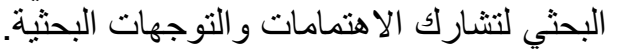
ج. ضرورة الاستفادة من تقنيات الويب الدالالي في تنظيم المعرفة في المؤسسات.

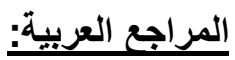

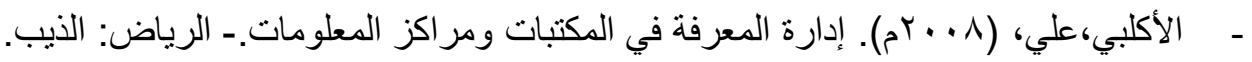

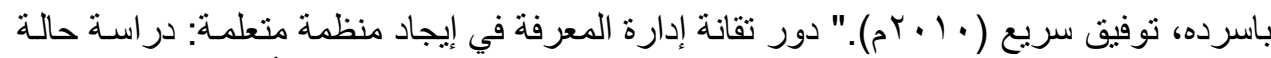

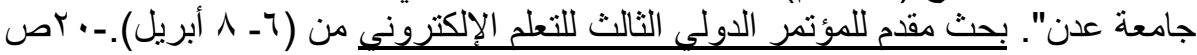

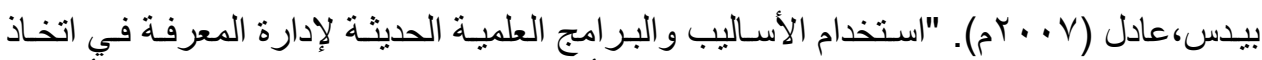

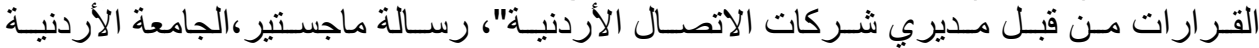

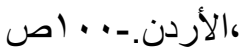

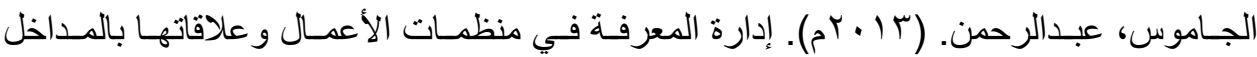

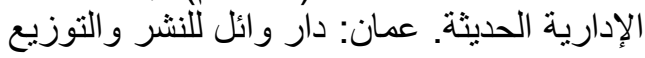

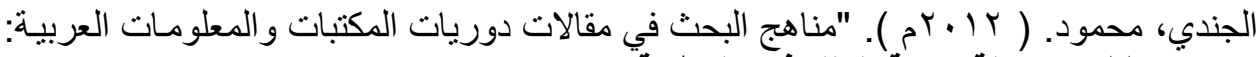

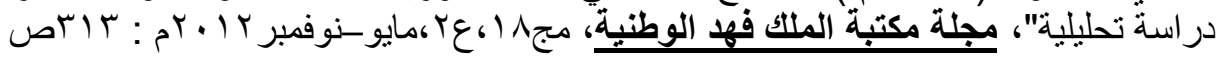

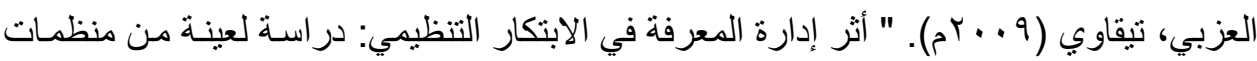

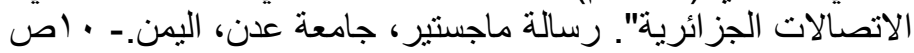

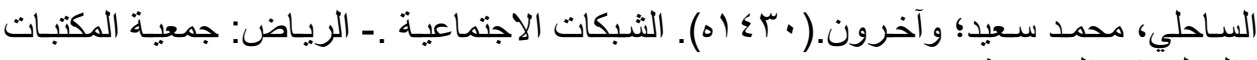
و المعلومات السعودية السية ولية

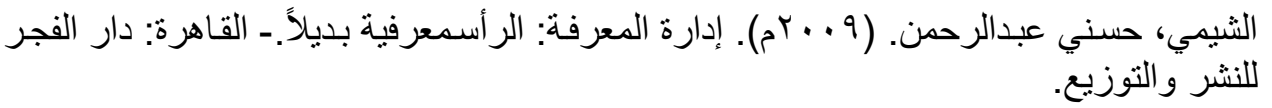

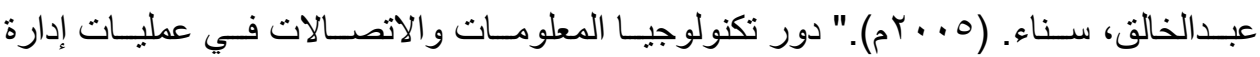

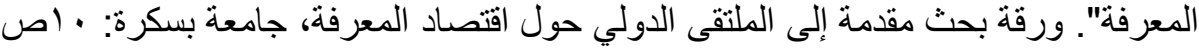

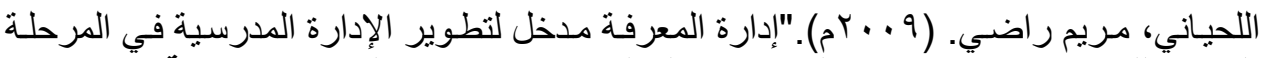

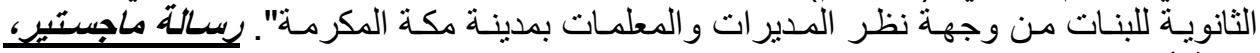
جامعة أم القرى:

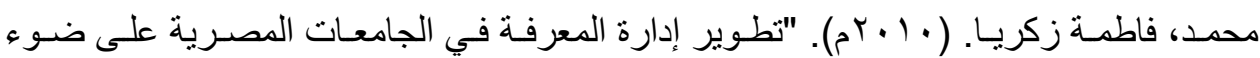

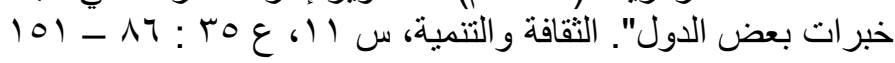

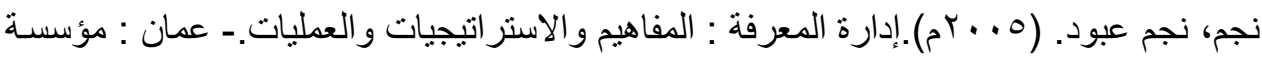

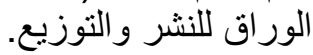




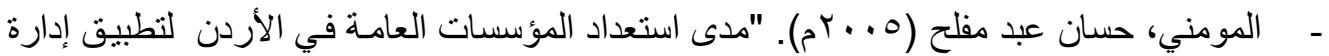

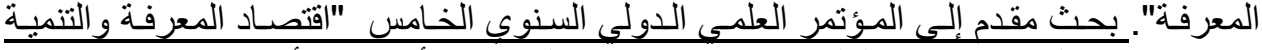

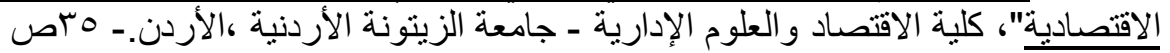

\section{REFERNCES:}

- $\quad$-Agung, Anak(2014). "Knowledge Management System Readiness Analysis: Case Study at Human Resource Consulting Company", Research paper part of the $2^{\text {nd }}$ International Conference on Technology, Informatics, Management, Engineering \& Environment.. Indonesia, Bandung, pp.205201, Access date 2020 From: https://ieeexplore.ieee.org/stamp/stamp.jsp?tp=\&arnumber=7011619

- $\quad$-Al-Alawi,A.\& A1-Marzoogi,N. \& Mohammad,Y. "Organizational culture and knowledge sharing: critical success factors". Journal of Knowledge Management, Vol. 11,No. 2,(2007)pp. 22-42

- -Almalky, Nabil A .(2019). " Knowledge Management in Human Resource in Oil Companies from Technologies Perspectives a Literature Review". International Journal of Engineering \& Technology, 8 (1.10) pp. 136-143

- -Daft, R. (2006). Organization Theory and Design, ThomsonLearning, South Western, U. S. A ,pp.200

- $\quad$-Hashemi, Parvin (2018). "Developing a domain ontology for knowledge management technologies". Online Information Review. Vol. 42 No. 1, pp. 28-44

- $\quad$-Jabar, Marzanah, Alnatsha, Abdallah (2014). "Knowledge Management System Quality: A Survey of Knowledge Management System Quality Dimensions, Research paper part of Computer and Information Sciences (ICCOINS),pp.1-5.2014 International Conference, Access date, 2020 From: https://ieeexplore.ieee.org/document/6868438

- $\quad$-Malafsky, G. \& Newman, B.D. (2004). "Organizing Knowledge with Ontologies and Taxonomies". Fairfax, VA. pp1-12

- $\quad$-Malhotra, Y.(2004). "Why Knowledge Management Systems Fail?

- Enablers and Constraints of Knowledge Management in Human

- Enterprises". Inc American Society for Information Science and Technology Monograph Series, pp. 87-112.

- $\quad$-Oseledchik, Mikhail.(2018)." Using Social Networks in Knowledge Management

- System".Social Science, Education and Humanities Research, vol. 205,pp.911-914 
- O'Sullivan.K.J, \& Azeem. S.W (2007) "An Analysis of Collaborative Group Structure Technological Facilitation from a KnowledgeManagement Perspective" The Electronic Journal of Knowledge Management. Vol. 5 Issue 2, pp 223 -230. Access date, 2020 From:www.ejkm.com

- Pulkkinen. J. (2008). " Knowledge Management and Emerging Technologies". Discussion Paper for Train4Dev. KM subgroup. pp1-5

- Rexwhite, T.(2017)." Information and communication technologies for knowledge management in academic libraries in Nigeria and South Africa".South African Journal of Information Management.pp 1-9

- -Santoro, G. (2017 )."The Internet of Things: Building a knowledge management system for open innovation and knowledge management capacity". Technological Forecasting and Social Change

- $\quad$-Turban, E. \& Aronson, J. (1998). "Decision Support Systems and Intelligent Systems", Prentice-Hall International, Inc., New Jersey, pp. 214-215.

- $\quad$-Young , Ronald .(2010).Knowledge Management Tools and Techniques Manual.Japan: Asian Productivity Organization. pp.94

- $\quad$-Zawiyah, M.Y.( 2014). "Preliminary Overview of Data Mining Technology for Knowledge Management System in Institutions of Higher Learning".World Academy of Science, Engineering and Technology, 74.pp.80-85.Access date, 2020 From:

- https://www.researchgate.net/publication/266971646 Preliminary Overv iew of Data Mining Technology for Knowledge Management System $s$ in Institution of Higher Learning

- - -Zyngier, Suzanne .(2014)."The role of technology in Knowledge Management: trends in the Australian corporate Environment ". pp.1-12 .Access date, 2020

From:https://www.researchgate.net/publication/228902643 The role of technolo-

gy in knowledge management trends in the Australian corporate e nvironment 